\title{
WHAT DOES HUMAN CAPITAL DO? A REVIEW OF GOLDIN AND KATZ'S THE RACE BETWEEN EDUCATION AND TECHNOLOGY
}

\author{
Daron Acemoglu \\ David Autor \\ Working Paper 17820 \\ http://www.nber.org/papers/w17820
NATIONAL BUREAU OF ECONOMIC RESEARCH
1050 Massachusetts Avenue
Cambridge, MA 02138
February 2012

We thank Lawrence Katz and Claudia Goldin for valuable and generous input. We are also indebted to Janet Currie for excellent editorial suggestions, Matthew Rognlie for superb research assistance and Andrew Garin for many thoughtful comments and edits. The views expressed herein are those of the authors and do not necessarily reflect the views of the National Bureau of Economic Research.

NBER working papers are circulated for discussion and comment purposes. They have not been peerreviewed or been subject to the review by the NBER Board of Directors that accompanies official NBER publications.

(C) 2012 by Daron Acemoglu and David Autor. All rights reserved. Short sections of text, not to exceed two paragraphs, may be quoted without explicit permission provided that full credit, including $\odot$ notice, is given to the source. 
What Does Human Capital Do? A Review of Goldin and Katz's The Race between Education and Technology

Daron Acemoglu and David Autor

NBER Working Paper No. 17820

February 2012

JEL No. J30,J31,O14,O31,O33

\begin{abstract}
Goldin and Katz's The Race Between Education and Technology is a monumental achievement that supplies a unified framework for interpreting how the demand and supply of human capital have shaped the distribution of earnings in the U.S. labor market over the 20th century. This essay reviews the theoretical and conceptual underpinnings of this work and documents the success of Goldin and Katz's framework in accounting for numerous broad labor market trends. The essay also considers areas where the framework falls short in explaining several key labor market puzzles of recent decades and argues that these shortcomings can potentially be overcome by relaxing the implicit equivalence drawn between workers' skills and their job tasks in the conceptual framework on which Goldin and Katz build. The essay argues that allowing for a richer set of interactions between skills and technologies in accomplishing job tasks both augments and refines the predictions of Goldin and Katz's approach and suggests an even more important role for human capital in economic growth than indicated by their analysis.
\end{abstract}

\author{
Daron Acemoglu \\ Department of Economics \\ MIT, E52-380B \\ 50 Memorial Drive \\ Cambridge, MA 02142-1347 \\ and CIFAR \\ and also NBER \\ daron@mit.edu \\ David Autor \\ Department of Economics \\ MIT, E52-371 \\ 50 Memorial Drive \\ Cambridge, MA 02142-1347 \\ and NBER \\ dautor@mit.edu
}




\section{Introduction}

Goldin and Katz's magnum opus, The Race between Education and Technology, rivals Becker's Human Capital in ambition and potential influence over the economics profession and beyond. Becker formulated a new and empirically fruitful framework for economists and policymakers to

think about skills - how they are used, how markets price them and how and why workers and firms invest in them. The way most economists currently think about the supply and demand for human capital is still largely shaped by Becker's insights. Goldin and Katz's book promises to be equally transformative. It is erudite, well researched, well written and interesting. Most importantly, it is a coherent and compelling account of how human capital has been the defining factor for the "American century" - mostly for America, but also for much of the industrialized world.

What is a reviewer to do? It is tempting to simply summarize the book's arguments and marvel at how well they are constructed. But not only would this make a tedious review, it would constitute a missed opportunity. Based on the hope that transformative contributions catalyze the literature in part by encouraging others to venture beyond their remit, we will take an alternative path. We will attempt instead to do justice to Goldin and Katz's accomplishment by pushing their argument further to frame some of the important questions that lie ahead on the agenda that they have established.

The Race between Education and Technology is a multilayered book with dozens of interesting and useful ideas and hypotheses, all supported with historical evidence and data. But its core, as we see it, is made up of the following four arguments:

1. U.S. leadership, which Goldin and Katz describe as U.S. 'exceptionalism,' in educational investments has visible economic, political and social roots that are related to specific characteristics of American society at the turn of the 20th century.

2. Human capital is a central determinant of economic growth, both in general and in the specific case of economic growth in the United States during the 20th century.

3. Investments in human capital can play a major equalizing role. Under the Tinbergian assumption that technology is skill-biased, technological progress will necessarily widen inequality among skill groups unless it is countered by increases in the supply of human capital. The steady accumulation of human capital has thus been the main equalizer in the U.S. labor market. The rise in inequality over the last three or so decades, in turn, can be understood as the consequence of a slowing rate of accumulation of human capital, which has not kept pace with skill-biased technological change. 
4. The United States has, to a significant degree, lost its educational leadership because its educational institutions have become decadent. This problem can be redressed through reform and re-investment.

We largely agree with all four of Goldin and Katz's arguments, in part because they are exposited so clearly and supported with compelling historical and econometric evidence. At the same time, however, acknowledging the multifaceted nature of human capital and understanding how it is allocated to a changing set of tasks broadens - in fact strengthens - the argument.

Underlying all four of Goldin and Katz's main arguments is a theory of "what human capital does," which is where the book connects closely with Becker's contribution on the theory of human capital. Human capital, according to this view, augments effective units of labor, thereby making workers more productive. Although human capital is potentially applicable to all jobs, tasks, occupations and industries, the demand for human capital is not uniform across all domains - that is, some activities are more skill-intensive than others. Consequently, increasing the supply of human capital to the economy will tend to increase the relative output of these skill-intensive activities and hence reduce the skill premium that educated workers command.

These observations in turn undergird what we refer to as the 'canonical model,' which is the conceptual centerpiece of the Goldin and Katz analysis. ${ }^{1}$ The canonical model builds on seminal contributions by Gary Becker, Jan Tinbergen - whose metaphorical race between education and technology inspires the book's title - Finis Welch, and, of course, the corpus of scholarship created by Goldin and Katz over more than two decades. In this model, technological progress raises the demand for skill, and human capital investments slake that demand. When demand moves outward faster than does the supply of human capital, inequality rises, and vice versa when supply outpaces demand.

The canonical model has withstood the test of time and has proven to be of ongoing relevance in analyzing and interpreting a rich and diverse set of facts. Nevertheless, by confronting this canonical model with the major developments in the U.S. economy and labor market over the course of a century, Goldin and Katz's analysis also underscores some of its limitations. What the canonical model does not deny, though largely leaves out, is that human capital is multidimensional. Workers produce work by performing job tasks, and different tasks require different types of skills. Workers with different types of skills have varying comparative advantages for these tasks. Changes in technology and in the supply of skills affect what types of tasks are in demand and how the available set of skills are assigned to these different tasks. This, we will argue, creates a rather different and more nuanced picture of "what human capital does." By

\footnotetext{
${ }^{1}$ Atkinson (2008) refers to this as the 'Textbook Model'.
} 
implication, it also leads to a somewhat different perspective on many of the developments in the United States' and other advanced nations' labor markets.

In Section 2, we start with a discussion of the first and second of their arguments and argue that Goldin and Katz's analysis can be extended further by placing more emphasis on the political economy of education in the United States and going beyond the standard growth accounting framework for measuring the contribution of human capital to U.S. economic growth. The bulk of our review will focus on the third argument, which centers around Goldin and Katz's synthesis of the standard model. This is presented in Section 3. In this section, we also present a review of several recent trends in the U.S. labor market which are challenging to this canonical model. In Section 4, we develop the argument that a theoretical framework based on the allocation of different types of human capital to distinct tasks may be a useful starting point for analyzing the patterns that are challenging for the canonical model. ${ }^{2}$ To do this, we provide a sketch of a baseline framework that incorporates these aspects, and we explain how this refined framework may contribute to a more holistic explanation for some of the empirical patterns motivating Goldin and Katz's synthesis and also strengthen their emphasis on the central role played by human capital in 20th-century U.S. growth. We conclude in Section 5 with a discussion of Goldin and Katz's fourth argument centering around the causes of - and potential remedies to - the decline in the U.S. education system, and how the task-based approach potentially complements their conclusions.

\section{The Human Capital Century}

Goldin and Katz forcefully argue that the 20th century was the "human capital century" for the United States and the world, and the United States' exceptional leadership in investing in the skills of its workforce was a major driver of economic growth. This is an important and compelling argument, though more remains to be said about why the United States was exceptional and how its investments in human capital contributed to growth.

\subsection{American Exceptionalism}

Goldin and Katz summarize American exceptionalism in schooling as follows:

"By the early twentieth century America educated its youth to a far greater extent than did most, if not every, European country. Secondary schools in America

\footnotetext{
${ }^{2}$ Notably, Goldin and Katz explore closely related ideas in other recent publications, for example, Autor, Katz and Kearney (2006, 2008) and Goldin and Katz (2007), but given their intended broad audience, focus on the canonical model in the book.
} 
were free and generally accessible, whereas they were costly and often inaccessible in most of Europe. Even by the 1930s America was virtually alone in providing universally free and accessible secondary schools." (page 12)

"The United States expanded its lead in education in the twentieth century by instituting mass secondary schooling and then establishing a flexible and multifaceted higher education system." (page 18)

Their Table 1.1 shows the striking contrast between the United Kingdom and the United States. In the late 1930 s, only about 38 percent of 14 -year-olds and 4 percent of 17 -year-olds were enrolled in school in the United Kingdom, while almost 68 percent of 14 to 17 -year-olds were enrolled in school in the United States. Goldin and Katz are absolutely correct to emphasize how consequential this mass schooling system was for U.S. society, and Chapter 4 of the book usefully pinpoints the several pillars that have supported this system: public funding, public provision, local decentralization, separation of church and state, gender neutrality, and the open and forgiving nature of the system. Their account also highlights the proximate factors that allowed mass schooling to thrive, including the presence of fiscally independent, mostly small districts, local property taxation, and local control over schools.

Nevertheless, the book does not provide a fully compelling answer to the question of why America became exceptional. In Chapter 1, Goldin and Katz suggest that a pivotal factor may have been the greater importance of general training based on formal schooling in America at a time when much of Europe relied on specific training on the job for investing in the skills of much of its non-elite population. While this characterization is no doubt accurate, it is not entirely clear why this distinction should by itself lead to substantially greater levels of public investment in the United States as well as greater openness and forgivingness of the educational system, particularly for non-elite students. The other factors Goldin and Katz emphasize, such as locally decentralized and independent school districts, and gender neutrality, also appear important in the development of the American education system. But why these choices have been made in the United States, and not elsewhere, is less clear.

A seemingly central factor that receives less attention than it deserves is political economyor, more crudely, politics. The unique educational institutions that are indigenous to the United States may have resulted not from optimal or even intentional design, but from a conflict in which the masses - the non-elite elements of society - were particularly successful in resisting elite designs. For example, setting up a society based on principles of equality, governed by the people through general assemblies and investing in their education through a mass schooling system, could not have been further from the plans of the leading members of the Virginia Company 
when they set about colonizing Jamestown. It was only when their strategy of capturing and enslaving locals and their next best alternative, putting the lower strata of the settlers brought in as indentured servants to work in gangs for the benefit of the elites and the Company, failed and was met with fierce resistance, that the beginning of U.S. institutions as we recognize them today started taking shape. The attempts to coerce the settlers were replaced by the 'headright system,' granting them land in 1618 and a General Assembly for the settlers to govern themselves in 1619. Similar events played out in Maryland, the Carolinas and elsewhere, with remarkably similar outcomes. The United States was first ahead of Europe not in its schooling system or other aspects of economic institutions, but in its politics. ${ }^{3}$ In the early 20 th century, the United States was again ahead of Europe in its responsiveness to the political wishes of the majority of the population. The Populist and Progressive movements contributed to the emergence of an era in which the government took actions against the monopoly of the Robber Barons and attempted to limit the extent to which the playing field had become highly uneven. ${ }^{4}$

Though more research is needed to determine the role of political factors in shaping the American schooling system, it seems plausible that the General Assemblies of the early colonial period were the mainstay of the open American schools, and the active involvement of the masses was a major contributor to the spread of mass schooling in the 20th century. Whether this is so is not merely of antiquarian interest. The answer bears on the critical contemporary question of whether the current barriers to upgrading schooling quality in the United States and elsewhere today are primarily fiscal and technological -i.e., realigning teacher incentives or selecting good principals - or whether they are fundamentally political in nature, an issue we return to below.

\subsection{The Contribution of Human Capital to Growth}

Goldin and Katz begin the book by stating:

"That the twentieth century was both the American Century and the Human Capital Century is no accident. Economic growth in the modern period requires educated workers, managers, entrepreneurs, and citizens. Modern technologies must be invented, innovated, put in place, and maintained. They must have capable workers at the helm." (pages 1-2, italics in the original).

\footnotetext{
${ }^{3}$ The other important factor emphasized by Goldin and Katz, the separation of church and state, probably also has political roots, related both for the factors emphasized here and the religious dissenters' impact on the development of these institutions. It is also possible, though speculative, that independent school districts and gender neutrality might also be a consequence of the same political and institutional developments.

${ }^{4}$ The discussion in this and the previous paragraph draws on Acemoglu and Robinson (2012) and Galenson (1996). These ideas are consistent with Goldin and Katz's discussion of the 'grassroots' nature of the early American education system.
} 
They are right both in emphasizing the importance of human capital for U.S. growth and identifying some of the mechanisms through which this has likely operated.

They also provide a careful accounting exercise to measure the extent to which increases in the human capital of the workforce have contributed to U.S. growth. This is based on the common approach in the growth literature, which posits an aggregate production function

$$
Y=F(K, X, A)
$$

summarizing the relationship between aggregate output, $Y$, the stock of physical capital, $K$, the stock of human capital, $X$ (e.g., measured as efficiency units of labor), and technology, $A$, measured as the residual from the accounting exercise. Here Goldin and Katz follow the economic growth literature in assuming that all forms of human capital enter the aggregate production function simply through the aggregate $X$. Moreover, the standard assumption in growth accounting exercises is that the function $F$ exhibits constant returns to scale in $K$ and $X$. Under these and additional assumptions that all factor markets are competitive and there are no technological (or human capital) externalities in production, and denoting the growth rate of variable $Z$ by $g_{Z}$ and the rental rate of capital by $R$, the growth rate of aggregate output can be expressed as (e.g., Acemoglu, 2009, Chapter 3):

$$
g_{Y}=g_{A}+\frac{R K}{Y} g_{K}+\frac{w_{X} X}{Y} g_{X}
$$

where $X$ is computed as the total stock ('efficiency units') of human capital. Finally, $g_{A}$ is interpreted as the contribution of technological change to economic growth, typically computed as the residual in such growth accounting exercises using data on the other variables in (2).

Goldin and Katz assume that $F$ takes a Cobb-Douglas form with the share of labor/human capital, $X$, equal to 0.7 , which implies that $w_{X} X / Y=0.7$ and $R K / Y=0.3$. They are more careful than many in the way they measure the stock of human capital in the economy, which they accomplish by aggregating micro data on hours across groups of workers with different education and demographic characteristics using observed wages as weights. This is the correct approach based on their assumptions, which are the standard assumptions in the literature. We discuss and critique the economic foundations of these assumptions in 4.3 below.

Nevertheless, Goldin and Katz's accounting exercise does not provide answers that are fully consistent with their emphasis on the role of human capital. Their Table 1.3 shows that on average less than 15 percent of U.S. growth is accounted for by the increase in the human capital of American workers according to this methodology, i.e., by the term $\left(w_{X} X / Y\right) g_{X}$. This does not look like the sort of number that would deserve the title "Human Capital Century". So why the discrepancy? 
Our view is that Goldin and Katz are right in emphasizing the centrality of human capital to economic growth, but the vehicle they use for measuring the contribution of human capital to this process does not do justice to the multifaceted role that human capital plays. The first problem, as Goldin and Katz make clear in the above-quoted passage and discuss further in the book, is that human capital is a major contributor to creation and adoption of frontier technologies. U.S. technological leadership in the world would not have been possible without the participation of a broad segment of the population in high-tech industries. U.S. workers were able to play this role because they had access to high-quality education by the standards of the time. But the growth accounting framework implicitly ignores the role of human capital investments in fostering technological change. To be clear, this is a limitation of the growth accounting model, not its end users. Goldin and Katz are acutely aware of this limitation and emphasize throughout the book the indirect contribution that education makes to growth, writing on page 40 that, "Although it is difficult to quantify these indirect contributions of education to economic growth, they are bound to have been quite large." 5

The second potential problem, which is intimately linked to the set of issues we highlight in our discussion in Section 4, relates to the impact of human capital on the productive use of new technologies. The root of this problem is again that the standard growth accounting framework does not allow for a rich interaction between the implementation and spread of new technologies and human capital. It is plausible that certain types of human capital are particularly useful when combined with the most advanced technologies. Formally, the degree of complementarity or substitutability between technologies and human capital may differ among technologies and over time. The canonical model that Goldin and Katz use for interpreting the relationship between human capital and the structure of wages, which we discuss in the next two sections, allows for this possibility but only in a limited form as we will argue in Section 4. Going beyond the canonical model to formally study these richer interactions may significantly enrich our understanding of the contribution of human capital to growth - in particular by explicitly linking the economic value of human capital to the set of tasks demanded in the economy.

But before we attempt to amend the canonical model, we first highlight its power and utility.

\footnotetext{
${ }^{5}$ Though the relationship between human capital and technological progress - the creation and adoption of new technologies - is beyond the scope of our review, it is useful to note that it operates at least through three channels. First, the human capital and access to education of the most talented individuals in society is probably the most important factor underpinning technological progress. Second, the human capital of the workforce may influence the pace of technological change both because of human capital externalities and because it changes the incentives for overall technological progress (as many technologies may not be profitable without the requisite skills from the workforce). Third and relatedly, the composition of human capital of the workforce potentially affects the direction of technological progress (e.g., Acemoglu, 1998). We will return to this issue briefly in the last section.
} 


\section{The Canonical Model and the Data}

Pronounced changes in the distribution of earnings and the returns to college over the last several decades have motivated a large literature exploring the relationship between technical change and wages. The starting point of this literature is the observation that the return to skills, as measured by the wages of college graduates relative to high school graduates, for example, has increased over multiple decades despite the large secular increase in the relative supply of college educated workers. This suggests that concurrent with the increase in the supply of skills, there has been an increase in the (relative) demand for skills. Following Tinbergen's pioneering (1974) work, the relative demand for skills is then linked to technology, and in particular to the skill bias of technical change. These ideas are elegantly and powerfully operationalized in the canonical model, which we present next. We then outline how the canonical model can be used to explain the evolution of skill in college premia and earnings inequality, and then we summarize some of the empirical trends that are challenging to interpret through the lens of this model.

\subsection{The Canonical Model}

The canonical model includes two skill groups performing two distinct and imperfectly substitutable occupations (or producing two imperfectly substitutable goods). ${ }^{6}$ Technology is assumed to take a factor-augmenting form, and thus complements either high or low skill workers. Changes in this factor-augmenting technology capture skill-biased technical change. In this approach, the college/high-school log wage ratio serves as a summary index of the premium that high skill workers command relative to low skill workers, and this premium is determined by the relative supply and demand for skills. The relative demand for skills increases over time because changes in technology are assumed to be 'skill biased,' in the sense that they demand relatively more, or are more complementary to, high skill workers. The steady increase in the relative supply over the last century and a half, due to both greater public investments in schooling and greater willingness of families and individuals to obtain schooling, leads to Tinbergen's famous race between education and technology (and the eponymous title of Goldin and Katz's book).

Suppose that the total supply of low skill labor is $L$ and the total supply of high skill labor is $H$. In particular, let us assume that workers are in one of two mutually exclusive groups, the set of low skill workers, $\mathcal{L}$, and the set of high skill workers, $\mathcal{H}$, and that there is heterogeneity in skills or efficiency units of labor. Then total supplies are given by $L=\int_{i \in \mathcal{L}} l_{i} d i$ and $H=\int_{i \in \mathcal{H}} h_{i} d i$,

\footnotetext{
${ }^{6}$ Early applications of this model to U.S. labor market include Welch (1974), Katz and Murphy (1992) and Goldin and Margo (1992). In many cases, this model is extended to more than two skill groups (see., e.g., Katz and Murphy, 1992, Card and Lemieux, 2001, and Acemoglu, Autor and Lyle, 2004).
} 
where $l_{i}\left(h_{i}\right)$ denotes the efficiency units of low (high) skill labor that worker $i$ possesses. ${ }^{7}$

The production function for the aggregate economy takes the following constant elasticity of substitution (CES) form

$$
Y=\left[\theta\left(A_{L} L\right)^{\frac{\sigma-1}{\sigma}}+(1-\theta)\left(A_{H} H\right)^{\frac{\sigma-1}{\sigma}}\right]^{\frac{\sigma}{\sigma-1}},
$$

where $\sigma \in[0, \infty)$ is the elasticity of substitution between high skill and low skill labor, $A_{L}$ and $A_{H}$ are factor-augmenting technology terms, and $\theta$ is a distribution parameter that determines the relative importance of low skill labor in the production function. The elasticity of substitution between high and low skill workers plays a pivotal role in interpreting the effects of different types of technological changes in the canonical model. ${ }^{8}$ In this framework, technologies are factor-augmenting, meaning that technological change serves to either increase the productivity of high or low skill workers (or both), so there are no explicitly skill-replacing technologies. ${ }^{9}$

Assuming that factor markets are competitive, unskilled and skilled wages, $w_{L}$ and $w_{H}$, are given by their marginal products, and can be obtained by differentiating (3). Combining these wages, we can also obtain the skill premium - the high skill wage divided by the low skill wage - as

$$
\omega=\frac{w_{H}}{w_{L}}=\frac{1-\theta}{\theta}\left(\frac{A_{H}}{A_{L}}\right)^{\frac{\sigma-1}{\sigma}}\left(\frac{H}{L}\right)^{-\frac{1}{\sigma}},
$$

which can be rewritten conveniently by taking logs,

$$
\ln \omega=\text { constant }+\frac{\sigma-1}{\sigma} \ln \left(\frac{A_{H}}{A_{L}}\right)-\frac{1}{\sigma} \ln \left(\frac{H}{L}\right) .
$$

This equation shows the two key forces in the Tinbergen model: changes in the skill-bias of technology, reflected in the evolution of $A_{H} / A_{L}$; and changes in the relative supply of skills, reflected in the evolution of $H / L$.

The (log) skill premium is important in part because it is a key market outcome, reflecting the relative price of skills in the labor market. The evolution of this skill premium is also the key yardstick in Goldin and Katz's analysis of the race between education and technology. Equation (5) shows that there is a simple log-linear relationship between the skill premium and the relative supply of skills as measured by $H / L$. Equivalently, equation (5) implies:

$$
\frac{\partial \ln \omega}{\partial \ln H / L}=-\frac{1}{\sigma}<0
$$

\footnotetext{
${ }^{7}$ The important assumption is that workers do not have a choice on whether to supply high or low skill labor to the market depending on prices or sets of tasks being performed in the economy.

${ }^{8}$ In studying the college/high-school premium, Goldin and Katz parameterize this elasticity as fixed. In studying the high-school graduate/dropout premium, they use a time-varying elasticity to allow high school graduate and high school dropout labor to become more substitutable over time.

${ }^{9}$ Shifts in $\theta$ can be thought of as skill-replacing technical changes in that they directly change the demand for one skill group at the expense of the other, and Goldin and Katz allow $\theta$ to be time-varying. This reduced-form method of modeling skill-replacing technical change is serviceable but does not have clear microfoundations and so is not commonly used in practice.
} 
This relationship corresponds to the second of the two forces in Tinbergen's race. For a given skill bias of technology, captured here by $A_{H} / A_{L}$, an increase in the relative supply of skills, $H / L$, reduces the skill premium with an elasticity of $1 / \sigma$.

The downward-sloping relationship between relative supply and the skill premium implies that if technology, in particular $A_{H} / A_{L}$, had remained roughly constant over recent decades, the remarkable increase in the supply of skills that occurred in the U.S. throughout the 20th century would have led to a significant decline in the skill premium. The lack of such a decline is a powerful piece of evidence for Goldin and Katz's conclusion that the first force in Tinbergen's race - changes in technology that raised the demand for skills - must have been important throughout the 20th century.

Formally, differentiating (5) with respect to $A_{H} / A_{L}$ yields:

$$
\frac{\partial \ln \omega}{\partial \ln \left(A_{H} / A_{L}\right)}=\frac{\sigma-1}{\sigma}
$$

Equation (6) implies that if $\sigma>1$ (i.e., high and low skill labor are gross complements), then relative improvements in the high skill augmenting technology (i.e., in $A_{H} / A_{L}$ ) increase the skill premium. This can be seen as a shift out of the relative demand curve for skills. ${ }^{10}$

The key equation of the canonical model, (5), links the skill premium to the relative supply of skills, $H / L$, and to the relative technology term, $A_{H} / A_{L}$. This last term is not directly observed. Nevertheless, we can make considerable empirical progress by taking a specific form of Tinbergen's hypothesis. For example, one can assume, as is generally done in the literature, that there is a log linear trend increase in the demand for skills over time caused by ongoing technological change, so that $\ln \left(A_{H, t} / A_{L, t}\right)=\gamma_{0}+\gamma_{1} t$, where $t$ is calendar time (and variables written with $t$ subscript refer to these variables at time $t$ ). Substituting this equation into (5), we obtain:

$$
\ln \omega_{t}=\text { constant }+\frac{\sigma-1}{\sigma} \gamma_{0}+\frac{\sigma-1}{\sigma} \gamma_{1} t-\frac{1}{\sigma} \ln \left(\frac{H_{t}}{L_{t}}\right) .
$$

Equation (7) implies that 'technological improvements' take place at a constant proportional rate, while the supply of skilled workers may grow at varying rates at different points in times.

\footnotetext{
${ }^{10}$ The converse is obtained when $\sigma<1$ : that is, when $\sigma<1$, an increase in $A_{H}$, relative to $A_{L}$, shifts the relative demand curve inward and reduces the skill premium. Consider, for example, how factor-augmenting technology change affects the wages of the augmented factor when the production function is Leontief (fixed proportions). In this case, as $A_{H}$ increases, high skill workers become more productive, and hence the demand for low skill workers increases by more than the demand for high skill workers. This observation raises an important caveat. It is tempting to interpret improvements in technologies used by high skill workers, $A_{H}$, as 'skill biased'. However, when the elasticity of substitution is less than 1, it will be advances in technologies used with low skill workers, $A_{L}$, that increase the relative productivity and wages of high skill workers, and an increase in $A_{H}$ relative to $A_{L}$ will be 'unskilled labor biased'. While the case of $\sigma<1$ is interesting, in the context of the substitution between college and non-college workers, a relatively high elasticity of substitution is both plausible and consistent with many studies. Most estimates put $\sigma$ in this context to be somewhere between 1.4 and 2, so we focus on this case throughout this essay.
} 
Changes in the skill premium will result when the growth rate of the supply of skills differs from the pace of technological progress: when $H / L$ grows faster than the rate of skill-biased technical change, $(\sigma-1) \gamma_{1}$, the skill premium will fall; when the supply growth falls short of this rate, the skill premium will increase.

Though most analyses of the canonical model focus on its implications for the skill premium, the model also has sharp predictions on the levels of wages. In particular, it can be verified easily that the model implies $\partial w_{L} / \partial A_{L}>0$ and $\partial w_{L} / \partial A_{H}>0$ (and similarly for $\partial w_{H} / \partial A_{H}$ and $\left.\partial w_{H} / \partial A_{L}\right)$. That is, factor-augmenting technical change increases wages of both low skill and high skill workers (except in the limiting cases where $\sigma=0$ and $\sigma=\infty$ in which case these inequalities can be weak). This result is intuitive. It will also turn out to be important: technological improvements of any sort will lead to higher wages for both skill groups in the canonical model. Thus unless there is 'technical regress,' the canonical model does not predict a decline in the real wage of a factor whose relative supply is not shifting outward.

\subsection{The Power of the Canonical Model}

To demonstrate the power and utility of the canonical model, we begin by replicating the influential analysis of Katz and Murphy (1992). Katz-Murphy used data from the Current Population Survey for earnings years 1963 through 1987 to explore the relationship between the relative supply of skills in the U.S. economy and the evolution of the skill premium. Specifically, they fit equation (7) to time-series measures (calculated from the CPS microdata) of the college/highschool relative wage and college/high-school relative labor supply for the years 1963 through 1987. Following their methods as closely as possible, the first column of Table 1 presents an OLS regression of the composition-adjusted college/high-school log weekly wage premium on a linear time trend and the log supply of college relative to high-school labor for years 1963-1987. We obtain the estimate:

$$
\ln \omega_{t}=\text { constant }+0.027 \times t-0.612 \cdot \ln \left(\frac{H_{t}}{L_{t}}\right) .
$$

As shown in Figure 1 as well as the first column of Table 1, this simple specification performs quite well in capturing the broad features of the evolving college premium between 1963 and 1987. Most notably, thete is a sharp reversal of the trajectory of the college premium coinciding with the deceleration in the growth of college relative supply in the late 1970s. The power of the model is underscored by Figure 2, which plots the college premium and college relative supply measures by year, each purged of a linear time trend. The robust inverse relationship between these two series demonstrates the key role played by the decelerating supply of college 
workers in driving the college premium upward in recent decades. More precisely, the estimates suggest that the evolution of the college premium during the period 1963 through 1987 can be characterized by an elasticity of substitution between college graduate workers and non-college workers of about $\hat{\sigma}=1 / 0.61 \approx 1.6$, and an annual increase of about 2.7 percent in the relative demand for college labor. ${ }^{11}$

Column 2 of Table 1 includes 21 additional years of data beyond 1987 to extend the KatzMurphy estimate to 2008. When fit to this longer time period, the model yields a substantially higher estimate of the elasticity of substitution, $\hat{\sigma} \approx 2.9$, and a slower trend rate of demand growth (1.6 percent annually). ${ }^{12}$ The proximate cause of this change in the model's estimated parameters can be seen in Figure 1, which, following Autor, Katz and Kearney (2008), plots the out-of-sample fit of the Katz-Murphy model for the years 1987-2008. The fit of the model remains quite good through the year 1992, five years out of sample. But the model systematically deviates from the data thereafter, predicting a sharper rise in the college premium than occurs. While the observed college premium rose by 12 points between 1992 and 2008, the model predicts a rise of $25 \log$ points.

Without further refinements to the model, the discrepancy between the observed and predicted growth of the college premium suggests that either the trend in relative demand decelerated after 1992 or the elasticity of substitution rose. Subsequent columns of Table 1 explore the first possibility by freeing up the linear time trend with less restrictive parameterizations: a linear spline that allows the time trend to deviate from its initial trajectory after 1992; a quadratic time trend; and a cubic time trend. When fit to the data, all three of these variants suggest a significant deceleration in the trend for the relative demand for college workers occurring sometime during the 1990s. Conditional on the more flexible time trend, the elasticity of substitution in these estimates returns to the range of 1.6 to 1.8. At face value, this model suggests that relative demand for college workers decelerated in the 1990s, which does not accord with common intuitions regarding the nature or pace of technological changes occurring in this era.

The simple exercise above highlights several strengths and limitations of the simple education race model. A key strength is parsimony. Using only two time series, one of relative wages, the other of relative supplies, Goldin and Katz show that the model does a remarkably good job of explaining the evolution of the skill premium over nine decades (from 1915 to 2005) and, by implication, quantifying the contribution of skill-biased technical change to this phenomenon.

\footnotetext{
${ }^{11}$ Our estimates are very similar, though not identical, to those of Katz and Murphy, who find an elasticity of substitution of 1.4 and a time trend of 3.3 percent.

${ }^{12}$ This point is explored by Card and DiNardo (2002), Autor, Katz and Kearney (2008), and Goldin and Katz (Table 8.2).
} 
Moreover, a host of careful studies, reviewed in Goldin and Katz and in Acemoglu and Autor (2010), confirm the explanatory power of this simple supply-demand framework for explaining trends in the college-versus-high-school earnings gap across other industrialized economies (most notably, the United Kingdom and Canada), among age and education groups within countries, and across birth states and birth cohorts within the United States.

But the data also reveal some puzzles for the model, which we highlight next. We then consider whether these puzzles can be potentially better addressed by an extended conceptual framework that permits a richer set of interactions among available skill supplies, technological change, and the assignment of both labor and capital to the set of tasks in use in the economy.

\subsection{Challenges for the Canonical Model}

\section{Observed versus Predicted Wage Inequality}

A first puzzle, already visible from Table 1 and Figure 1, is that from the early 1990s to the present, wage inequality (as measured by the college/high-school log wage gap) rose substantially less than predicted by the model. This divergence may or may not be important in its own right - after all, the model is still qualitatively on target - but it raises the question of what has changed. A second notably divergent pattern, seen in Figure 5 and highlighted in earlier work by Autor, Katz and Kearney (2006 and 2008), is that since the early 1990s, wages in the top, middle and bottom of the income distribution have evolved in quite distinct and somewhat unexpected directions. Most notably, while both the 90th and 10th percentiles of the weekly and hourly wage distributions diverged rapidly from the median from the early 1980s to the early-1990s - consistent with a rising return to skill in the canonical model - the gap between the 10th percentile and the median substantially contracted over the next 15 years even as the 90/50 gap continued to rapidly expand. This suggests that, at the very least, it may be useful to distinguish between high, middle and low skill workers rather than just between high and low skill workers as is typically done in the canonical model.

\section{Falling Real Wages of Low Skill Workers}

Another fact that underscores the shortcomings of the canonical model is the surprising evolution of real (rather than relative) wage levels. The canonical model of factor-augmenting technical change robustly predicts that demand shifts favoring skilled workers will raise the skill premium and boost the real earnings of all skill groups (e.g., college and high school workers), as highlighted above. This prediction appears strikingly at odds with the data, as first reported by Katz and Murphy (1992) and shown in Figure 3. ${ }^{13}$ This figure plots the evolution of real

\footnotetext{
${ }^{13}$ For compactness, we plot data for male workers only.
} 
log earnings by gender and education for the same samples of full-time, full-year workers used above. Each series is normalized at zero in the starting year of 1963, with subsequent values corresponding to the log change in earnings for each group relative to the base year. All values are deflated using the Personal Consumption Expenditure Deflator produced by the U.S. Bureau of Economic Analysis.

Figure 3 reveals three key facts about the evolution of earnings by education groups that are not evident from the earlier plots of the college/high-school wage premium. First, a sizable share of the increase in college relative to non-college wages in 1980 forward is explained by rising wages of post-college workers, i.e., those with post-baccalaureate degrees. Real earnings for this group increased steeply and nearly continuously from at least the early 1980s to present. By contrast, earnings growth among those with exactly a four-year degree was much more modest. For example, real wages of males with exactly a four-year degree rose 13 log points in the three decades between 1979 and 2008. This appears paltry when compared to the 20 log point increase in male college wages in the first ten years of the sample.

A second fact evident from the figure is that a major proximate cause of the growing college/high-school premium is steeply declining wages among less educated workers - especially less educated males - rather than rising wages among college workers. Real earnings of males with less than a four year college degree fell steeply between 1979 and 1992, by 12 log points for high school and some-college males, and by 20 log points for high school dropouts. Low skill male wages modestly rebounded between 1993 and 2003 but never reached their 1980 levels. For females, the picture is qualitatively similar but the slopes are more favorable. While wages for low skill males were falling in the 1980s, wages for low skill females were largely stagnant; when low skill male wages increased modestly in the 1990s, low skill female wages rose approximately twice as fast. ${ }^{14}$

The third key fact evident from Figure 3 is that while the earnings gaps between somecollege, high school graduate, and high school dropout workers expanded sharply in the 1980s, these gaps stabilized thereafter. In particular, the wages of high school dropouts, high school graduates, and those with some college moved largely in parallel from the early 1990s forward.

\section{Polarization of Earnings Growth}

The net effect of these three trends - rising college and post-college wages, stagnant and falling real wages for those without a four-year college degree, and stabilizing wage gaps among some-

\footnotetext{
${ }^{14} \mathrm{~A}$ potential concern with the interpretation of these results is that the measured real wage declines of lesseducated workers mask an increase in their total compensation after accounting for the rising value of employer provided non-wage benefits such as healthcare, vacation and sick time. This concern is discussed in Acemoglu and Autor (2010) and dismissed drawing largely on Pierce (2001 and 2010) and Hamermesh (1999).
} 
college, high school graduates, and high school dropout workers - is that starting in the past two decades, earnings growth has become increasingly non-monotone in skill and wage levels, with more rapid growth at the upper and (surprisingly) lower deciles of the wage distribution than at the median.

This pattern is seen in Figure 4, which plots changes in hourly wages relative to the change at the median by earnings percentile among male workers between 1974 and 2008. ${ }^{15}$ We divide the sample into two time intervals that roughly capture the changing dynamics of earnings inequality. During the initial period of 1974 through 1988, the monotonicity of wage changes by percentile is evident. Equally visible is the U-shaped (or 'polarized') growth of wages by percentile in the 1988 through 2008 period. Interestingly, the steep gradient of wage changes above the median is nearly parallel for these two time intervals. Thus, the key difference between these periods turns on the evolution of the lower tail, which fell steeply in the 1980s and then regained ground relative to the median thereafter.

This U-shaped growth of wage levels over the last two decades is clearly difficult to interpret in a model with only two skill groups. One can of course posit that the levels and distribution of $h$ and $l$ - the distribution of efficiency units of high and low skill labor within the populationshifted in a manner that generates apparent non-monotonicity even with only two underlying skill prices. But without supporting evidence, this explanation appears ad hoc.

\section{Occupational Polarization}

Accompanying the wage polarization depicted above is a marked pattern of job polarization, by which we mean the simultaneous growth of employment in high skill, high wage occupations and low skill, low wage occupations. Figure 5 illustrates this phenomenon by plotting the change over each of the last three decades in the share of U.S. employment accounted for by 318 detailed occupations encompassing all of U.S. employment and ranked (on the $x$-axis) by their skill level from lowest to highest. Here, an occupation's skill rank is proxied by the average wage of its workers in 1980. The $y$-axis of the figure corresponds to the change in employment at each occupational percentile as a share of total U.S. employment during the decade. Since the sum of shares must equal one in each decade, the change in these shares across decades must total zero. $^{16}$

The figure reveals a striking reversal of occupational employment changes between the early

\footnotetext{
${ }^{15}$ Consistent hourly earnings data are available for the period 1973 through 2008 from the Current Population Survey. To increase precision, we pool three adjacent years of data for each series.

${ }^{16}$ These series are smoothed using a locally weighted regression to reduce jumpiness when measuring employment shifts at such a narrow level of aggregation. Due to smoothing, the sum of share changes may not integrate precisely to zero.
} 
and later years of the sample, paralleling the polarization of earnings. Between 1979 and 1989, occupational employment growth was nearly monotone in occupational skill; occupations below the median declined as a share of employment and occupations above the median increased. Between 1990 and 2007, relative employment growth was again most rapid at high percentiles but it was also strongly positive at lower percentiles, with the growth of occupational employment shares almost as rapid at the 10th percentile as at the 80th percentile.

Figure 6 documents the broad changes in occupational structure that drive job polarization in the United States by plotting the change in employment by decade for the years 1979 through 2010 for 10 major occupational groups encompassing all of U.S. non-agricultural employment. We separately plot the three recession years of 2007 through 2010 so as not to conflate cyclical with secular changes.

The occupations depicted in the figure cluster into three broad groups. On the right-hand side of the figure are managerial, professional and technical occupations. These are highlyeducated and highly-paid occupations. Employment growth in these occupations was robust throughout the three decades plotted. Even in the years 2007 through 2010, during which U.S. employment fell by approximately 7 million workers, these occupations experienced almost no absolute decline in employment.

Moving towards the center of the figure, the next four columns display employment growth in 'middle-skill occupations,' comprised of four categories: office and administrative support occupations; sales occupations; production, craft and repair occupations; and operator, fabricator and laborer occupations. The first two categories are white-collar occupations that are disproportionately held by women with a high school degree or some college. The latter two categories are blue-collar occupations that are disproportionately held by males with a high school degree or lower education. While the headcount in these occupations rose in each interval depicted between 1979-2007, their growth rate lagged the economy-wide average and, moreover, generally slowed across decades. These occupations were hit particularly hard after 2007, with absolute declines in employment ranging from 7 to 17 percent.

Finally, the left-most three columns of Figure 6 depict employment trends in service occupations, which the Census Bureau defines as jobs that involve helping, caring for or assisting others. The majority of workers in service occupations have no post-secondary education, and hourly wages in these occupations are generally below the other seven categories depicted. Employment growth in service occupations has been consistently positive over the past three decades. Indeed, Autor and Dorn (2011) show that rising service occupation employment accounts for most of the upward twist of the lower tail of Figure 5 during the 1990s and 2000s. All three subcategories of service occupations - protective services, food preparation and cleaning services, and personal 
care - expanded by double digits in the 1990s and the pre-recession years of the past decade (1999 through 2007). Protective service and food preparation and cleaning occupations also expanded rapidly during the 1980s. Notably, even after 2007, employment growth in service occupations was modestly positive despite the deep recession-more so, in fact, than the three high skill occupations on the right-hand side of the figure. ${ }^{17}$

This pattern of employment polarization is not unique to the United States. Goos, Manning and Salomons (2009, Table 1) show that for each of 16 European Union countries for which data were available for the years 1993 through 2006, employment in low-wage occupations increased relative to employment in middle-wage occupations, with a mean gain in employment in low relative to middle wage occupations of 10 percentage points. This cross-country analysis suggests that job polarization is at least as pronounced in the European Union as in the United States.

Cumulatively, these two trends - rapid employment growth in both high and low-education jobs - have substantially reduced the share of employment accounted for by 'middle skill' jobs. In 1979, the four middle skill occupations - sales, office and administrative workers, production workers, and operatives - accounted for 58.9 percent of employment. In 2007, this number was 47.5 percent, and in 2010 , it was 44.5 percent.

\section{Challenges for the Canonical Model: Summing Up}

We believe that these discrepancies between the data and the predictions of the canonical model - specifically, the heterogeneous behavior of the top, middle and bottom of the earnings distribution, falling real wages of some skill groups, polarization of earnings growth, and polarization of occupational growth - are sufficiently important to warrant enriching the canonical model to gain leverage on these trends. We turn to this task next. Subsequently, we briefly revisit these facts to ask whether the enhanced model can in fact offer leverage.

\section{Beyond the Standard Model}

Many of the shortcomings of the canonical model can, we believe, be overcome by relaxing the implicit equivalence between workers' skills and their job tasks in the model. In our terminology, a task is a unit of work activity that produces output. A skill is a worker's stock of capabilities for performing various tasks. Workers apply their skills to tasks in exchange for wages. Thus, the task-based approaches emphasize that skills are applied to tasks to produce output-skills do not directly produce output. The distinction between skills and tasks is irrelevant if workers of a given skill always perform the same set of tasks. The distinction becomes important, however,

\footnotetext{
${ }^{17}$ The employment share of service occupations was essentially flat between 1959 and 1979. Their rapid growth since 1980 marks a sharp trend reversal.
} 
when the assignment of skills to tasks is evolving with time, either because shifts in market prices mandate reallocation of skills to tasks or because the set of tasks demanded in the economy is altered by technological developments, trade, or offshoring.

To highlight how a task-based approach can enrich and strengthen the emphasis of Goldin and Katz, we summarize a simple task-based framework proposed in Acemoglu and Autor (2010), which builds on Autor, Levy and Murnane (2003), Acemoglu and Zilibotti (2001) and Costinot and Vogel (2010). Goldin and Katz have also explored closely related ideas in other recent publications, for example, Autor, Katz and Kearney (2006, 2008) and Goldin and Katz (2007), but have chosen not to focus on them in the book given their intended broad audience. ${ }^{18}$ Distinct from the canonical model, this framework explicitly incorporates the possibility that technological change or international trade will cause some tasks previously performed by domestic workers to either be replaced by capital or substituted by workers abroad. This provides a natural mechanism through which technological advances - importantly even factor-augmenting technological change - can lead to real declines in the wages for certain groups of workers as well as non-monotone changes in the structure of employment by occupation.

The model also has two foundational features that we view as particularly useful. First, it nests the canonical model as one parametric case; thus, this model builds upon rather than dispenses with the many strengths of the canonical model. Secondly, the model removes what we think of as an artificial set of distinctions typically made between labor, capital, and trade (or offshoring) in canonical models of production where different factors of production play distinct and often incommensurate roles. In the current model, the fundamental units of production are job tasks, which are combined to produce output. Tasks can be supplied by domestic labor, foreign labor, or capital, the capabilities of which may change over time. The allocation of both labor and capital to tasks is determined in equilibrium by comparative advantage, which is in turn a function of factor-task specific productivities and the market clearing price of each factor.

\subsection{A simple model of tasks and skills}

We consider a static environment with a unique final good. For now, the economy is closed and there is no trade in tasks (a possibility we allow for later). The unique final good is produced by combining a continuum of tasks represented by the unit interval, [0,1]. Suppose, to simplify the analysis, that the technology combining the services of tasks is a constant elasticity of

\footnotetext{
${ }^{18}$ They have instead gone some way towards incorporating the notion of skill-replacing technical changes we focus on here by making the distribution parameter in the CES production function (3), $\theta$, time-varying. As commented in footnote 9 , this is somewhat ad hoc as it is unclear what sorts of changes in technology would affect $\theta$.
} 
substitution aggregator, so that the final good is produced as

$$
Y=\left[\int_{0}^{1} y(i)^{\frac{\eta-1}{\eta}} d i\right]^{\frac{\eta}{\eta-1}},
$$

where $Y$ denotes the output of a unique final good, $y(i)$ is the 'service' or production level of task $i$, and $\eta$ is the elasticity of substitution between tasks. Acemoglu and Autor (2010) studied the 'Cobb-Douglas' case where $\eta=1$, or equivalently, $\ln Y=\int_{0}^{1} \ln y(i) d i$. For our discussion here, it is sufficient to focus on this case.

Suppose that there are three types of labor, high, medium and low skill workers, who inelastically supply $L, M$ and $H$ units of labor respectively. At any given point in time, a subset $\mathcal{I} \subset[0,1]$ of the potentially feasible tasks is available (the remaining tasks cannot be produced). Each of the available tasks has the following production function

$$
y(i)=A_{L} \alpha_{L}(i) l(i)+A_{M} \alpha_{M}(i) m(i)+A_{H} \alpha_{H}(i) h(i)+A_{K} \alpha_{K}(i) k(i),
$$

where $A$ terms represent factor-augmenting technology, and $\alpha_{L}(i), \alpha_{M}(i)$ and $\alpha_{H}(i)$ are the task productivity schedules, designating the productivity of low, medium and high skill workers in different tasks. In particular, $\alpha_{L}(i)$ is the productivity of low skill workers in task $i$, and $l(i)$ is the number of low skill workers allocated to task $i$. The remaining terms are defined analogously. Similarly, $\alpha_{K}(i)$ is the task productivity schedule of capital and $k(i)$ is the amount of capital allocated to task $i$. Analogously to the canonical model, we can think of $A_{L}, A_{M}$ and $A_{H}$ as low, medium and high skill factor, factor-augmenting technological changes. Distinct from the canonical model, however, a factor-augmenting technological change need not increase the wages of all factors in this setup, as we subsequently discuss.

Though each task can be performed by low, medium or high skill workers or by capital, the comparative advantage of skill groups differs across tasks, as captured by the $\alpha$ terms. These differences in comparative advantage are central to understanding the interplay of tasks and skills. In particular, we impose the following simple structure of comparative advantage: $\alpha_{L}(i) / \alpha_{M}(i)$ and $\alpha_{M}(i) / \alpha_{H}(i)$ are (strictly) decreasing. This assumption can be interpreted as stating that higher indices correspond to 'more complex' tasks in which high skill workers are better than medium skill workers and medium skill workers are better than low skill workers. Though not very restrictive, this assumption ensures a particularly simple and tight characterization of equilibrium in this economy. We ignore for the moment the task productivity schedule of capital. ${ }^{19}$

\footnotetext{
${ }^{19}$ The canonical model can be nested within this framework trivially by ignoring middle skill workers and assuming that $\alpha_{L}(i)=\alpha_{L}>0$ and $\alpha_{H}(i)=0$ for all $i \leq \bar{\imath}$ and $\alpha_{L}(i)=0$ and $\alpha_{H}(i)=\alpha_{H>0}$ for all $i>\bar{\imath}$. Acemoglu and Autor (2010) discuss other ways in which the model admits special cases similar to the canonical model.
} 
Factor market clearing requires

$$
\int_{0}^{1} l(i) d i \leq L, \int_{0}^{1} m(i) d i \leq M \text { and } \int_{0}^{1} h(i) d i \leq H .
$$

The structure of the model's equilibrium is derived in Acemoglu and Autor (2010), and we provide only minimal details here. Because of the simple structure of comparative advantage outlined above, the equilibrium of the model involves a partition of the continuum of tasks into three adjacent sets: the least complex set of tasks, those on the interval $0 \leq i \leq I_{L}$, will be supplied by $L$ workers; an intermediate set of tasks on the interval $I_{L}<i \leq I_{H}$ will be supplied by $M$ workers; and the remaining highest skill set on the interval $I_{H}<i \leq 1$ will be supplied by $H$ workers. Crucially, $I_{L}$ and $I_{H}$, which are the cut-points of the task partition, are endogenously determined in the model.

Competitive labor markets require that the law of one price for skill applies. Each unit of $L$ labor will receive a wage $W_{L}$, and similarly for units of $M$ and $H$ labor. Additionally, since each task can potentially be performed by any skill group, the allocation of tasks to skill groups is governed by a no arbitrage condition: for the marginal task located at $I_{L}$, the cost of performing this task must be identical in equilibrium whether it is supplied by $L$ or $M$ workers. Similarly, the cost of performing task $I_{H}$ must in equilibrium be equated between $M$ or $H$ workers. For tasks on the interior of these sets $\left(i<I_{L}, I_{L}<i<I_{H}\right.$, and $\left.i>I_{H}\right)$, however, workers of the relevant skill groups hold strict comparative advantage. Using these conditions, it is straightforward to demonstrate that there will exist a unique $I_{L}^{*}$ and $I_{H}^{*}$ that jointly satisfy the law of one price, the no arbitrage condition, and the market clearing condition in (10).

\subsection{Implications for Interpreting Patterns of Wages and Employment}

A key strength of the model presented above is that it facilitates a more nuanced view of the nature of technological shifts, which, together with changes in the supply of skills, underlie the bulk of the changes in the earnings distribution over the last several decades. At a basic level, the distinction between high, middle and low skills adds an important degree of freedom to the model, allowing for non-monotone movements in wage levels and wage inequality as seen in the data.

A second distinction is that, while factor-augmenting technological improvements always increase the real earnings of both skilled and unskilled workers in the canonical model, this may not be so in the presence of endogenous allocation of workers to tasks. Acemoglu and Autor (2010) show that a factor-augmenting technological improvement (e.g., an increase in $A_{H}$ ) can reduce the wages of middle skill workers. In particular, this happens when new technologies, by increasing the productivity of high skill workers, encourage some of the tasks previously 
performed by middle skill workers to be shifted to high skill workers, but a corresponding shift of low skill tasks to middle skill workers is not profitable. ${ }^{20}$

Arguably the most important innovation offered by this task-based framework is that it can be used to investigate the implications of capital (embodied in machines) directly displacing workers from tasks that they previously performed. In general, we expect that tasks performed by all three skill groups are subject to machine displacement. Based on the patterns documented in the data above, as well as the general characterization of machine-task substitution offered by Autor, Levy and Murnane (2003), however, we believe the set of tasks most subject to machine displacement in the current era are those that are routine or codifiable. ${ }^{21}$ Such tasks are primarily, though not exclusively, performed by medium skill workers (e.g., high school graduates and those with less than a four-year college degree). For this reason, let us suppose that there now exists a range of tasks $\left[I^{\prime}, I^{\prime \prime}\right] \subset\left[I_{L}, I_{H}\right]$ for which $\alpha_{K}(i)$ increases sufficiently (with fixed cost of capital $r$ ) so that they are now more economically performed by machines than middle skill workers. For all the remaining tasks, i.e., for all $i \notin\left[I^{\prime}, I^{\prime \prime}\right]$, we continue to assume that $\alpha_{K}(i)=0$.

What are the implications of this type of technological change for the supply of different types of tasks and for wages? We answer this question formally in Acemoglu and Autor (2010). Even without such a formalization, however, it is straightforward to see why this form of technological change has the potential to generate the patterns of wage changes and polarization documented above: a task-replacing technological change can directly reduce wages of a skill group even as it raises total output. Intuitively, a task-replacing technological change squeezes out the type of worker previously performing these tasks, thereby creating 'excess supply.' Consequently, these workers are reallocated to tasks for which they have lower comparative advantage, which pushes their wages down. Simultaneously, by reducing the cost, and hence increasing the intensity of use, of the newly automated tasks, the task-replacing technological change complements each of the remaining tasks performed by labor.

Though these countervailing effects imply that the real wage of the group that is directly displaced by technology in a subset of its original tasks does not have to fall in real terms, such an outcome is possible - perhaps even likely —in realistic cases. In consequence, the task-based framework sketched above can readily rationalize falling real wage levels for some skill groups.

This set of observations explains why middle-skill task-replacing technological change can lead to wage polarization. By eroding the initial comparative advantage of the middle-skill group

\footnotetext{
${ }^{20}$ Loosely, this happens when $I_{H}$ shifts down considerably while $I_{L}$ does not change by much.

${ }^{21}$ Tasks with these attributes may also be particularly well suited to offshoring since their codafiability makes them readily tradeable as the price of communications falls (also a technological change).
} 
in a given set of tasks, the technological shift in effect shunts the displaced skill group into a set of tasks in which it was initially less productive. This depresses the group's wage relative to both $L$ and $H$ workers. $^{22}$

The polarization of occupational employment also follows from this mechanism. As demonstrated in the plots above, the occupations that have contracted most rapidly as a share of total employment over the last three decades are reasonably well characterized as routine taskintensive activities. Specifically, many of the tasks historically performed by production, clerical, administrative support and sales workers have become fallow for automation as the cost of computer hardware has declined and the sophistication of software has advanced. Notice, however, that this process does not imply that these displaced tasks are obsolete - in fact, just the opposite. As the cost of performing routine tasks has declined by orders of magnitude, their use in production has grown explosively - think, for example, of the amount of processing power that goes into a single Google query. However, because these tasks are now performed by capital rather than labor, the consequences for the earnings power of workers who previously held comparative advantage in these tasks are at best ambiguous.

This process potentially catalyzes labor market polarization because as workers are displaced from routine task-intensive occupations, a greater mass of skills is reallocated towards the tails of the occupational distribution - both towards high skill analytic, reasoning and problem solving tasks and, ironically, towards traditionally low skill, in-person service tasks. Hence, this conceptual framework can readily accommodate what computer scientists refer to as Moravec's paradox, specifically, that "it is comparatively easy to make computers exhibit adult level performance on intelligence tests or playing checkers, and difficult or impossible to give them the skills of a one-year-old when it comes to perception and mobility" (Moravec, 1988, p. 15).

We do not wish to suggest that this model resolves the puzzles posed above; to some degree, it was purpose-built to interpret them. Our claim - or at least our hope - is that this framework is a productive conceptual tool for confronting key facts that currently lie beyond the canonical model's scope. We next ask whether this same framework redresses any of the limitations of the standard growth accounting exercise above.

\footnotetext{
${ }^{22}$ As detailed in Acemoglu and Autor (2010), there are also interesting general equilibrium effects on other skill groups. As the middle-skill group is displaced, the task boundaries will change, encroaching on the other two skill groups. The relative degree of encroachment on $L$ versus $H$ workers depends on the shape of the comparative advantage schedules in the neighborhood of the initial set boundaries. If $H$ workers have strong comparative advantage relative to $M$ in their initial tasks, then the upper boundary will move little. If $L$ workers have relatively weak comparative advantage in their initial tasks, then the predominant direction of task reassignment will be that tasks previously performed by $L$ workers are reallocated to $M$ workers.
} 


\subsection{Rethinking the Contribution of Human Capital to Growth}

As we saw above, Goldin and Katz quantify the contribution of human capital to economic growth using an accounting framework with human capital represented as a single aggregate factor. This choice may at first appear at odds with Goldin and Katz's emphasis on the canonical model in which there is a central distinction between skilled and unskilled labor (e.g., the aggregate production function (3)). Nevertheless, their approach is justified under the standard assumptions used in the literature, as we now explain. As is well known, Solow-type growth accounting recovers the contribution of different factors of production and technology under three conditions: the aggregate production function exhibits constant returns to scale; there are no production externalities (so that market prices capture social marginal products); and changes in each factor are small.

Under these assumptions, one can indeed use an aggregate of human capital, $X$, constructed as efficiency units of labor, in place of separate measures of skilled and unskilled workers. This follows because the growth accounting approach uses a first-order approximation to the aggregate production function, and this approximation is arbitrarily close to the underlying function when we consider small enough changes in factor supplies. To illustrate this point in greater detail, consider a hybrid of (1) and (3) with capital and skilled and unskilled labor, $L$ and $H$ :

$$
Y=\tilde{F}\left(K,\left[\left(A_{L} L\right)^{\frac{\sigma-1}{\sigma}}+\left(A_{H} H\right)^{\frac{\sigma-1}{\sigma}}\right]^{\frac{\sigma}{\sigma-1}}\right)
$$

where the production function $\tilde{F}$ exhibits constant returns to scale. The growth accounting equation in this case, with a logic similar to (2), can be written as

$$
g_{Y}=g_{A}+\frac{R K}{Y} g_{K}+\frac{w_{L} L}{Y} g_{L}+\frac{w_{H} H}{Y} g_{H},
$$

where $g_{Z}$ again denotes the growth rate of variable $Z$, and $g_{A}$ is the contribution of technological progress, driven, for example, by changes in $A_{L}$ and $A_{H}$, again computed as the residual from the growth accounting exercise.

Instead of entering the supply of unskilled and skilled labor, $L$ and $H$, directly into the growth accounting exercise, however, one can aggregate them into a single stock of human capital using the following measure of the aggregate stock of human capital,

$$
X=L+\frac{w_{H}}{w_{L}} H=L+\omega H .
$$

This approach will find an identical contribution of human capital to growth as in the full accounting framework in (12) for small enough changes in factor supplies. ${ }^{23}$ In consequence,

\footnotetext{
${ }^{23}$ To see this equivalence result, recall that $X$ denotes total efficiency units of labor as defined in (13). From this
} 
Goldin and Katz's use of an aggregate human capital measure in the place of separate skill groups in the growth accounting exercise does not cause their analysis to underestimate the contribution of human capital to growth.

Nevertheless, one of the assumptions upon which the growth accounting exercise relies is potentially problematic: specifically, that changes in the factors of production over time are small so the first order approximation in equation (12) is stable. This assumption is formalized in the growth accounting framework and in the above treatment by considering derivatives with respect to continuous time, so changes over time are arbitrarily small. If, however, there are large changes in factor supplies or technologies that alter the shares of factors in national income, all of these equations become rough approximations that can in principle go wrong. ${ }^{24}$

Given the rapid increase in the supply of different types of human capital and the consequent changes in prices, which Goldin and Katz themselves comprehensively document, this assumption of factor share stability may not be a good approximation to reality. In this case, correctly specifying the functional form of the aggregate production function, including the exact form of substitution between different types of skills, becomes crucial. ${ }^{25}$ Using an aggregate production function that does not distinguish between skilled and unskilled labor may then understate (or overstate) the contribution of human capital to growth.

This concern becomes more salient when the multifaceted nature of human capital and the endogenous allocation of this human capital to tasks is taken into account. This is not only because the pattern of substitution between different types of human capital becomes richer, but also because the value of different types of human capital crucially depends on the set of (evolving) tasks.

To elaborate on this point, let us return to the task-based framework introduced in this section and suppose, as seems plausible, that in the U.S. economy, the increase in educational attainments went hand in hand with expansions in the set of tasks $\mathcal{I}_{t}$ - e.g., from $\left[0, \bar{I}_{t}\right]$ to $\left[0, \bar{I}_{t+1}\right]$, where $\bar{I}_{t+1}>\bar{I}_{t}$. This simultaneous increase in human capital and the complexity of job tasks employed in the economy implies that changes in the prices of different skills will

definition, it follows that if $X$ is properly measured, $w_{X}$ will be the same as the unskilled wage, $w_{L}$ - essentially all labor is remunerated as different efficiency units of unskilled labor. Now differentiating (13), and rearranging, we also have

$$
g_{X}=\frac{L}{X} g_{L}+\frac{\omega H}{X} g_{H}
$$

Substituting this into (2), the growth accounting equation from Section 2 , and using the fact that $w_{L}=w_{X}$, we recover (12), the growth accounting equation from the production function explicitly distinguishing skilled and unskilled labor.

${ }^{24}$ In fact, Goldin and Katz do impose the Cobb-Douglas functional form between physical and human capital, as a further functional form restriction.

${ }^{25}$ See Acemoglu and Zilibotti (2001), where this point is raised in the context of the use of similar techniques in cross-country data. 
depend on the changes in the set of tasks in use. For instance, if the periods in which there are large increases in the supply of the highest type of human capital are also those in which there is a large expansion in the set of tasks (i.e., $\bar{I}_{t+1}$ is significantly greater than $\bar{I}_{t}$ ), then using an approximation to the production function that keeps the set of tasks at $\left[0, \bar{I}_{t}\right]$ may seriously underestimate the contribution of human capital to growth.

\subsection{Some Initial Evidence from U.S. States}

The ideas discussed in the previous subsection are speculative and there is no hard evidence as yet to suggest that they are empirically relevant. In this section, we take a first step towards exploring them empirically, and we provide suggestive evidence they are a productive avenue for understanding the interaction between human capital and economic growth. To do this, we extend the regression framework proposed by Krueger and Lindahl (2001) for estimating the role of human capital in cross-national development. Our extension of their approach allows for interactions between the set of tasks in use in the economy and the contribution of human capital to growth. If indeed the contribution of human capital to growth crucially depends on the set of tasks in use, we would expect such interactions to be significant and quantitatively important. Applying this framework to U.S. states, for which we have access to high quality data on schooling and measures of tasks (occupations) in use, we find evidence that the contribution of human capital to state-level output and growth does importantly depend on the set of tasks currently in use.

Krueger and Lindahl quantify the cross-country relationship between human capital and economic growth by estimating OLS models of the following form:

$$
\Delta Y_{j, t}=\beta_{1} \Delta S_{j, t}+\beta_{2} S_{j, t-1}+\beta_{3} Y_{j, t-1}+\beta_{4} \bar{I}_{j, t-1}+\delta_{t}+\varepsilon_{j, t}
$$

In this equation, $\Delta Y_{j, t}$ is the change in the logarithm of GDP per capita in country $j$ over time interval $t, \Delta S_{j, t}$ is the change in country $j$ 's average years of completed schooling, $S_{j, t-1}$ is the level of schooling at the start of period $t, Y_{j, t-1}$ is the start of period GDP, and $\delta_{t}$ denotes a full set of time effects. This specification is motivated by a macroeconomic aggregation of the micro-founded Mincerian worker-level earnings equation, which derives a log-linear relationship between years of completed schooling and hourly earnings. ${ }^{26}$ Initial GDP is included in the macroeconomic estimating equation to allow for income convergence among countries (implying

\footnotetext{
${ }^{26}$ The log-linear specification arises because workers must be compensated for foregone labor earnings while attending school, meaning that the (net) return to schooling must be roughly equal to the real rate of interest (see, e.g., Acemoglu, 2009, Chapter 10). The quadratic function in years of potential experience typically used in microeconomic wage equations is excluded from the macro-level model at the country level because years of potential experience are highly correlated with expected lifespan, which is itself a function of economic development and hence GDP.
} 
that $\beta_{3}<0$ ), while inclusion of initial schooling allows for the possibility that a larger stock of human capital may facilitate innovation and use of new technologies that boost GDP (implying that $\left.\beta_{2}>0\right){ }^{27}$

Fitting several variants of this simple model to a panel of countries, Krueger and Lindahl conclude that both the change in and start-of-period level of schooling are robust predictors of GDP growth, and that measurement errors in cross-national measures of average schooling levels tend to substantially attenuate estimates of $\beta_{1}$. To increase the signal to noise ratio in measures of $\Delta S_{j t}$ and reduce this attenuation problem, Krueger and Lindahl recommend estimating equation (14) in long differences of 5, 10 or 20 years.

In Table 2, we apply this approach to estimating the relationship between education and economic growth for the time interval of 1960 through 2007. Following the cross-country growth literature, our dependent variable is the change in the log of state per-capita income (PCI), which we obtain from decennial Census estimates for the years 1960 through 2000 and from the American Community Survey pooled samples from 2006 through 2008. ${ }^{28}$ We calculate years of schooling for state residents ages 18 through 65 using Census and ACS samples available from IPUMS (Ruggles et al. 2010). In addition to the regressors used by Krueger and Lindahl, we construct a proxy for the range of tasks in use in each state, denoted by $\mathcal{I}_{t}$ above, measured as the start-of-period fraction of state employment in professional, managerial and technical occupations. Higher values of this occupational specialization measure, $\bar{I}_{j, t}$ in our model, would imply that states produce with a larger range of tasks.

The first column of Table 2 presents an estimate of (14) for pooled, state-level changes in log GDP over (approximately) two-decade intervals between 1960 and 2007. Consistent with Krueger and Lindahl's cross-country results, column (1) of Table 2 shows a strong, positive relationship between growth of average schooling and PCI across states. A one year increase in school attainment predicts 9.7 log points of PCI growth, which is comparable both to Krueger and Lindahl's estimates (Table 3, page 1119) and to recent microeconomic estimates of the return to a year of schooling in the United States and other English-speaking countries (Oreopoulos and Salvanes, 2011). Additionally, the column (1) estimate shows that PCI growth was considerably more rapid in states with initially higher GDP and with a greater share of initial employment in complex occupations.

The next three columns of Table 2 extend the Krueger and Lindahl framework to investigate the complementarities between human capital and the set of tasks in use by estimating the

\footnotetext{
${ }^{27}$ When the rate of return to schooling increases over time, $\beta_{2}$ will also be positive.

${ }^{28}$ Sources: The Census data are available at http://www.census.gov/hhes/www/income/data/historical/state/state3.html. The ACS data were obtained from the American FactFinder http://factfinder.census.gov.
} 
following augmented version of (14)

$$
\Delta Y_{j, t}=\beta_{1} \Delta S_{j, t}+\beta_{2} S_{j, t-1}+\beta_{3} Y_{j, t-1}+\beta_{4} \bar{I}_{j, t-1}+\beta_{5} \Delta S_{j, t} \bar{I}_{j, t-1}+\delta_{t}+\varepsilon_{j, t},
$$

where we have added an interaction term between growth of state schooling levels and initial state task complexity, $\Delta S_{j t} \bar{I}_{j, t-1} \cdot{ }^{29}$

Consistent with our expectations founded on the task-based framework presented above, in column (2) we find that this interaction term is estimated at 1.43 and is highly significant (standard error $=0.42$ ). This suggests that a one year increase in average educational attainment leads to about 7 log points additional growth in PCI over two decades in a state that has 5 percentage points higher initial share of employment in complex occupations (relative to a state with mean task complexity). ${ }^{30}$ This gain is over and above the $8.6 \mathrm{log}$ points increase in PCI per year of education for the average state.

In columns (3) and (4), we also include the interaction between PCI and the change in schooling, $\Delta S_{j, t} Y_{j, t-1}$, either by itself or together with our variable of interest, $\Delta S_{j, t} \bar{I}_{j, t-1}$. We find no significant interaction between the change in schooling and initial state per capita income, suggesting that it is not simply wealthier states that appear to gain more from schooling but rather states specialized in more skill-intensive activities.

The last four columns of Table 2 extend the estimating equation by allowing for different slopes on years of post-secondary schooling and years of primary plus secondary schooling. ${ }^{31}$ An intriguing pattern that emerges from this extended model is that growth in schooling below the post-secondary level is a strong predictor of state level PCI growth whereas growth in post-secondary schooling has an economically small and statistically insignificant predictive relationship to state growth. Conversely, the interaction term between initial task-complexity and growth in years of post-secondary schooling is large and highly significant, while the interaction between initial task-complexity and growth of lower years of schooling is essentially zero. This pattern again suggests that, consistent with our task-based framework, the value of human capital investments appears to be conditional on the set of tasks in use, with greater gains for higher levels of schooling where task complexity is higher. ${ }^{32}$

\footnotetext{
${ }^{29}$ We de-mean each of the variables used to construct the interaction terms to eliminate the mechanical covariance between the main effects of these constituent variables and the resulting interaction terms.

${ }^{30}$ The mean of the complex occupation share variable rises from 0.21 in 1960 to 0.38 in 2007 . Its cross-state standard deviation is between 0.036 and 0.049 per decade.

${ }^{31}$ The primary plus secondary measure is calculated as the mean years of schooling completed in grades 1 through 12, while the post-secondary measure is the mean years of schooling completed in grades higher than 12 .

${ }^{32}$ Recent work by Hanushek and Woessmann (2008) emphasizes the role of school quality rather than quantity in fostering cognitive skills that raise productivity and hence incomes. Viewed through this lens, one might conjecture that the task complexity measure in our regressions serves as a proxy for school quality and, similarly, the positive interaction between increased schooling and task complexity indicates that schooling raises income by
} 
Though we offer these estimates as preliminary evidence on potential complementarities between job task demands and worker skills, we have carried out a number of tests to confirm the basic robustness of these patterns. When these models are fit using 10-year rather than 20-year long differences, we obtain qualitatively comparable results. Additionally, we have estimated these models using two alternative measures of state income other than the Census per-capita income measure. These are state personal income per capita from the Bureau of Economic Analysis and state level log weekly wage and salary income, calculated from Census and ACS microdata. Both alternative measures lead to similar results. ${ }^{33}$ The general pattern of results is also not sensitive to whether regressions are weighted by state population or whether each state is accorded equal weight, as in our estimates above. ${ }^{34}$

In net, we take these results to suggest that the relationship between human capital and economic growth may be richer and also more contingent than the simple growth accounting model suggests. These findings are in the spirit, if not the letter, of the emphasis in Goldin and Katz's book, as underscored by the quotation at the beginning of subsection 2.2. While they do not explore these dynamics in depth, they go beyond the simplest application of the growth accounting framework and highlight that allowing for a richer set of interactions between education and technology (reflected in the range of tasks in use) may provide additional insights into the role of human capital in economic growth.

\section{What the Future May Hold}

The final part of Goldin and Katz's argument is about the erosion of the forces that had fueled the rapid growth of education and underpinned the "American Century." In this section, we summarize their arguments on the challenges facing the United States and their policy recommendations. We then discuss the implications of the task-based approach to human capital about what the challenges are and what the future might hold.

more when school quality is higher. One reason for skepticism about this interpretation, however, is that we fail to detect any similar positive interaction between increases in schooling and per capita income in Tables 2 and 3 . Since we would expect per capita income to be a stronger proxy for worker productivity - and hence educational quality - than task complexity per se, we suspect that the task complexity measure is not primarily serving as a proxy for school quality.

${ }^{33}$ We prefer the PCI measure to the wage income measure; PCI is closely related to the outcome measure, GDP, used in the education and growth literature. We prefer the Census PCI to the BEA PCI measure because the construction of the Census measure is more transparent, and involves fewer imputations and (to our knowledge) no filtration.

${ }^{34}$ Similarly, estimates are little changed by dropping Hawaii and the District of Columbia. 


\subsection{Challenges to the U.S. Human Capital Machine}

Goldin and Katz give a characteristically detailed and nuanced account of how the United States has fallen behind in the quantity and quality of schooling, and what could be done to counteract this trend.

Two distinct but related problems are apparent. First, whereas the United States was the leader in high school graduation and then college graduation for much of the 20th century, over the last 30 years it has become something of a laggard in both as compared to other industrialized nations. Figure 7, which plots U.S. secondary school completions from 1930 through 1992, shows that American high school graduation rates peaked in the early 1960s and have stagnated since. ${ }^{35}$ Figure 8, which plots the supply of young (0 to 9 years of potential experience) male and female college relative to high school graduates in the U.S. labor market between 1963 and 2008, shows that the trends in college completion are equally discouraging. Despite the surge in the college premium, which Goldin and Katz document in detail and which is also visible in Figure 2 above, there has not been a robust supply response among recent cohorts. The net effect of these trends is that the United States is in the middle of the OECD pack both in terms of high school and college graduation - and this, from a country that surpassed almost all others in both categories as late as the 1960s.

Second, the United States is also lagging behind in terms of school quality, particularly in K-12. Goldin and Katz are careful to note that AP calculus students in the United States compare favorably with the advanced mathematics students in almost any country, while the average U.S. student lags behind the average student in most OECD countries in math and science. This quality deficiency is almost as worrying as the lack of progress in the high school and college graduation margin.

Goldin and Katz rightly emphasize the role of the slowdown in the quantity and quality of schooling in the surge in the U.S. earnings inequality: both the canonical model and variations thereof along the lines of our task-based framework suggest that without this slowdown, the college/high-school earnings gap and various other skill premia would have risen by less, and thus inequality in the U.S. labor market may not have become as pronounced. They also correctly dismiss claims that high school and college completion rates may have reached a natural plateau or that the return to additional human capital accumulation in the United States is low. Most likely, American youth are failing to get a sufficient amount and quality of schooling despite — not because of - the rewards to higher skills in the U.S. labor market.

So what can be done to reverse the U.S.'s educational decline?

\footnotetext{
${ }^{35}$ This figure is comparable to Figure 9.2 of Goldin and Katz but additionally includes separate series for graduation rates by sex for the years for which these data are available (1930 through 1982).
} 
Goldin and Katz identify the root of the problem to be the failure of the U.S. school system to ensure high quality education for more disadvantaged Americans. The U.S. school system is not performing well overall, but it is failing particularly for poor, minority and immigrant children. ${ }^{36}$ The problem is not necessarily that the U.S. school system has declined in absolute quality, but that the skill requirements of the workplace have risen and, simultaneously, the challenges that schools face in managing the diversity and poor school preparedness of a substantial fraction of the student population have mounted. The net result is that the average U.S. high school student graduate has only modest preparation in core subject areas - reading, writing, mathematics and analytical reasoning - and this in turn reduces U.S. college enrollment and completion rates, and likely compromises the quality of the human capital acquired in college.

Goldin and Katz suggest three sets of policies to set U.S. education back on the right track. The first is to devote additional resources to programs such as Head Start that would invest in the health and education of disadvantaged preschoolers, and improve the preparedness of these students before they enter the K-12 schooling system. The second is to channel more resources into K-12 schooling-for example, to reduce class size, particularly in school districts serving disadvantaged families. The third is to make financial aid for students seeking higher education more broadly available, more generous, and more transparent.

They also note that one of the great virtues of the U.S. schooling system, its decentralized and local structure, may have become a barrier to some of these changes. In recent decades, this decentralization has arguably increased the racial and income segregation of U.S. students while making it more difficult to orchestrate national efforts to "lift all boats." Finally, they also rightly note that even if their proposed policies were highly effective, they would do little to limit income inequality at the top. Hence, to the extent that the social objective is to create more equitable growth, not just to increase economic growth, Goldin and Katz suggest that a return to more progressive taxation would also be necessary.

While Goldin and Katz's proposed policies are, in our view, sound ones, their diagnosis of the maladies facing the U.S. human capital machine may be unduly narrow, focusing almost entirely on the educational system itself, and not sufficiently on the inputs on which this system draws and the political infrastructure that underpins it. Indeed, there are several facts revealed by Goldin and Katz's analysis that broadly hint that the U.S. educational system cannot be the sole cause of the waning educational stature of the United States. One such clue is found in Figure 7 (as well as Figure 9.2 of Goldin and Katz). The stagnation of U.S. K-12 graduation rates did not slowly take root over decades, as one would expect from an educational system in secular

\footnotetext{
${ }^{36}$ This is not to deny that the quality of education for many middle-class children can also be increased substantially, but it is the most disadvantaged students who are most badly served.
} 
decline. Rather, 75 years of improving U.S. secondary school graduation rates came to a sudden and nearly complete halt in the mid-1960s and remained more or less fixed at that plateau for the next three decades. It seems implausible that this sudden stop in U.S. educational progress is attributable exclusively to a discontinuous, permanent deterioration in the quality of the U.S. secondary school system in the mid-1960s. Other factors are thus likely to be at play.

A similarly jarring picture of discontinuous change is seen in the evolution of U.S. college completion rates one decade later. Figure 8 shows that America's rising college completion rate sharply decelerated in the mid-1970s, with this deceleration concentrated among U.S. males. In the ensuing 35 years, male four-year college completion rates have increased only very modestly. Meanwhile, after losing momentum during the 1970s, female four-year college completion rates have surged in the most recent two decades. Notably, the slight aggregate decline in the U.S. high school graduation rate since the early 1960s is driven almost exclusively by a declining male high school completion rate. The female graduation rate has remained nearly constant throughout the past forty years (Heckman and LaFontaine 2010).

As with the 'sudden stop' in U.S. secondary school graduation rates a decade earlier, it seems implausible that the U.S. higher education system became abruptly dysfunctional for males in 1974 even as its prowess at educating females improved. The fact that the flagging output of the U.S. educational machine afflicts primarily one of its two product lines - males - and that this fall-off takes place virtually discontinuously across birth cohorts suggests to us that the causal forces are broader and more pervasive than can be reasonably explained by discontinuous changes within the U.S. educational system itself. What are these broader causal forces? We do not believe that social science has so far produced an adequate account of what went wrong with the U.S. human capital machine. Our claim is therefore a modest one: the deterioration of the U.S. K-12 educational system is unlikely to be a sufficient explanation for the sharp stagnation of high school completion rates in the early 1960s and the slowdown in male post-secondary attainment commencing in the mid-1970s.

While we do not fully agree with Goldin and Katz's diagnosis of why the United States is losing the educational race, we concur that the additional human capital investments that they propose have some potential to improve matters - particularly by increasing the school preparedness of U.S. children prior to their entering K-12. But this brings us to a second barrier to reversing America's educational slide which does not receive sufficient attention from Goldin and Katz's analysis: politics. As it was politics that largely underpinned American schooling exceptionalism, fundamental reforms and significantly expanded investments in the U.S. education system would only be possible if the political will is found to support them. Research by political scientists and economists alike (e.g., summarized in Bartels, 2008) suggests 
that the U.S. political system has been giving much more weight to the rich and wealthy and much less to the poor. If the political voice of minority and low-income Americans remains limited, it is unlikely that the sort of broad-based and far-reaching investments in the schooling of the most disadvantaged that Goldin and Katz advocate will be undertaken.

\subsection{Implications and Caveats from a Complementary View}

Goldin and Katz highlight the decaying state of the U.S. education system and the challenge that this poses to U.S. leadership in human capital and economic performance. They suggest that bold action is necessary and could reverse the tide. As we discussed in the previous subsection, there is much to agree with in this assessment. We now conclude with a brief discussion of how an approach that emphasizes the multifaceted nature of human capital and how it is allocated to different and changing set of tasks may lead to further ideas and some refinements. Since much of our discussion below follows from an as-yet-untested perspective, it is inevitably speculative,

and we will just list some of the ideas as potential directions for further thoughts rather than conclusive implications backed up by a body of evidence.

1. Goldin and Katz stress the importance of increasing the supply and quality of human capital as a way of ensuring more rapid and more equitable growth. This is likely to be the right emphasis, though the framework outlined in Section 4 also underscores that it is particularly important to distinguish the growth implications of this predicament from its distributional consequences. In particular, if new technologies are indeed replacing many tasks previously performed by middle skill workers and are also expanding the set of tasks that high skill workers can perform, then the most important type of investments for U.S. economic growth might be those at the top of the human capital distribution. In terms of the framework presented above, a decline in the quality of schooling may reduce the efficiency units of labor supplied by low and medium skill workers, but in a world in which there is a rapid expansion of the set of advanced tasks demanded, combined with offshoring of middle and lower skill tasks, economic growth may still continue apace as long as the supply of very highly skilled labor to the economy continues to expand. Since, as Goldin and Katz mentioned and we noted above, U.S. elite high schools and (even more so) elite colleges remain among the best in the world, and assuming that the United States retains its ability to attract the best and brightest from other countries, the country could plausibly continue to generate substantial innovation and technological progress and achieve relatively high rates of economic growth even in the face of ongoing mediocrity in 'average' schooling. 
Thus, if our only policy objective was to ensure the fueling of the U.S. 'engine' of economic growth, the educational state of the Union might not be as alarming as it first appears. But on this path, the U.S. economy may quite plausibly fail to create high-paying, rewarding and stable jobs for a large fraction of its population. In this view, the most alarming problem posed by the current educational system for the U.S. economic model is not one of stagnating economic growth but rather one in which a rising tide fails to raise all boats. As new technologies continue to replace the tasks performed by medium and low skill labor, the gap between economic growth and equitable growth may widen - unless a larger share of U.S. workers is prepared to perform the work that is made particularly valuable as the competencies of contemporary technologies continue to improve.

2. These considerations suggest the need for a two-pronged approach. First, we have to ensure that the U.S. system does not invest too little at the top, missing out on providing the best human capital and most attractive entrepreneurial environment for the next generation of innovators. Stated bluntly, the 'elitism' of the U.S. educational system is a strength that we would not sacrifice, even in the service of the worthy goal of improving the system on average. Simultaneously, the United States must strive to improve the efficacy and efficiency of K-12 and pre-K education to provide the bulk of the workforce the skills needed to prosper in a rapidly changing environment. Whether or not this is essential for economic growth, it is indispensable for ensuring a more equitable distribution of (pre-tax) incomes and, arguably, a well-functioning democracy.

3. Relatedly, technological change and increases in incomes may create more jobs in services and in the 'ecosystem' related to new products rather than in assembly and actual production. These may not take us back to a world in which high school graduates can have generous benefits through union jobs and high wage growth, but may still create opportunities for workers who make appropriate vocational investments. As noted above, one of the ironies of the computer era is that information technology has increased labor's comparative advantage in traditionally low skill service tasks, such as food preparation and personal care, relative to its value in traditional middle skill tasks such as computation, information processing, and repetitive production activities. Improving workers' capabilities to add value in these tasks is therefore more important than ever. While one may legitimately be skeptical that education can do much to improve productivity in labor-intensive, technologically-lagging tasks, it is well worth noting that workers with post-secondary ed- 
ucation appear to earn more in essentially all walks of life -including mundane service occupations - than do those with a high school or lesser education (Carnevale, Rose and Cheah, 2011). This suggests that increasing the skills and capabilities of even workers that will perform the lower skill tasks in the economy - the $l_{i}$ 's or the efficiency units of labor of low skill workers - may be both beneficial for the efficiency of the aggregate economy and for containing inequality.

4. One potential misreading of the implications of the task framework is that the U.S. should give up on 'middle skill' education because there is no future for middle skill jobs. This inference is mistaken for two reasons. First, education is cumulative; students cannot attain high skills (e.g., proving theorems) without first mastering middle skills (e.g., arithmetic). Not providing such skills to all students would mean foreclosing their higher education options at an early age - an idea that is profoundly antithetical to the foundational virtues upon which Goldin and Katz argue America's educational and economic preeminence were built.

A second reason why middle skills will remain important is that while many middle skill tasks are susceptible to automation, many non-college jobs demand a mixture of tasks from across the skill spectrum. To take one prominent example, medical paraprofessional positions - radiology technicians, phlebotomists, nurse technicians, etc.-are a numerically significant and rapidly growing category of relatively well-remunerated, middle skill occupations. While these paraprofessions do not require a college degree, they do demand one to two years of post-secondary vocational training - and mastery of 'middle skill' mathematics, life sciences, and analytical reasoning is indispensable for success in this training. While important subsets of middle skill occupations are on the wane (e.g., clerical and repetitive production positions), we do not forecast the demise of all or even most middle skill jobs soon. The simple reason is that the many of the tasks currently bundled into these jobs will not readily be unbundled into separate labor and capital components with machines performing the 'middle skill tasks' and workers performing the residual. In numerous occupations, the coordination costs entailed by such an extreme division of labor are likely to be formidable. Thus, there will remain an important stratum of non-college jobs that demand the foundational 'middle' skills that a high quality secondary education provides.

5. The response of technologies to other labor market trends also needs to be considered in formulating forecasts and remedies about the problems of the U.S. education system. 
Models of endogenous, directed technological change - as discussed in footnote 5 - suggest that technologies will tend to become biased in favor of factors that are becoming more abundant and/or more profitable to utilize (Acemoglu, 1998, 2007). This suggests that as U.S. workers become more educated, the direction of technological change may adjust to demand more of those skills available in the market. The implications of this endogenous technology response could cut both ways. If the lowest-skill workers become a declining minority, technological change may pass them by, diminishing the likelihood that economic growth will benefit the bottom of the income distribution. However this is not the only possibility. As pointed out above, a responsive and successfully reformed education system would increase the skills of even the workers performing the lower skilled tasks (e.g., the $l_{i}$ 's). But if so, fostering technological change that complements the growing numbers of workers with the education and capability to utilize new technologies may become an attractive channel by which all boats may be lifted.

6. Finally, if our emphasis above that the U.S. human capital century was underpinned by politics is correct, then it becomes particularly important to consider how the United States will form the political coalitions needed to support a renewed focus on investing in the quality of education, both at the top and the bottom of the distribution.

\section{References}

Acemoglu, Daron. 1998. "Why do New Technologies Complement Skills? Directed Technical Change and Wage Inequality." Quarterly Journal of Economics 113(4), 1055-1090.

Acemoglu, Daron. 2007. "Equilibrium Bias of Technology." Econometrica 75(5), 1371-1410.

Acemoglu, Daron. 2009. Introduction to Modern Economic Growth, Princeton University Press, Princeton.

Acemoglu, Daron, David Autor and David Lyle. 2004. "Women, War and Wages: The Effect of Female Labor Supply on the Wage Structure at Mid-Century." Journal of Political Economy $112(3), 497-551$.

Acemoglu, Daron and David Autor. 2010. "Skills, Tasks and Technologies: Implications for Employment Earnings." In: Ashenfelter, O., Card, D. (Eds.), The Handbook of Labor Economics, vol. 4b. Elsevier, Amsterdam, 1043-1171.

Acemoglu, Daron and James Robinson. 2012. Why Nations Fail: Origins of Power, Poverty and Prosperity. (Forthcoming).

Acemoglu, Daron, and Fabrizio Zilibotti. 2001. "Productivity differences." Quarterly Journal of Economics 116(2), 563-606. 
Atkinson, Anthony B., 2008. The Changing Distribution of Earnings in OECD Countries (The Rodolfo De Benedetti Lecture Series). Oxford University Press, New York.

Autor, David and David Dorn, 2011. "The Growth of Low-Skill Service Jobs and the Polarization of the U.S. Labor Market." MIT Working Paper, June.

Autor, David, Lawrence F. Katz, and Melissa Kearney. 2006. "The Polarization of the U.S. Labor Market." American Economic Review Papers and Proceedings 96(2),

Autor, David, Lawrence F. Katz, and Melissa Kearney. 2008. "Trends in US Wage Inequality: Re-Assessing the Revisionists." Review of Economics and Statistics 90(2), 300-323.

Autor, David, Frank Levy and Richard Murnane. 2003. "The Skill Content of Recent Technological Change: An Empirical Exploration." Quarterly Journal of Economics 118(4), 1279-1334.

Bartels, Larry. 2008. Unequal Democracy: The Political Economy of the New Gilded Age. Princeton University Press, Princeton.

Card, David and John DiNardo. 2002. "Skill Biased Technological Change and Rising Wage Inequality: Some Problems and Puzzles." Journal of Labor Economics 20(4), 733-783.

Card, David, and Thomas Lemieux. 2001. "Can Falling Supply Explain the Rising Return to College for Younger Men? A Cohort-Based Analysis." Quarterly Journal of Economics 116(2), 705-746.

Carnevale, Anthony, Stephen Rose and Ban Cheah. 2011. "The College Payoff: Education, Occupations, Lifetime Earnings." Georgetown University Center on Education and the Workforce.

Costinot, Arnaud and Jonathan Vogel. 2010. "Matching and Inequality in the World Economy." Journal of Political Economy 118(4), 747-786.

Galenson, David, 1996. "The Settlement and Growth of the Colonies: Population Labor, and Economic Development." In Engerman, S. L., Gallman, R.E (Eds.), The Cambridge Economic History of the United States. Cambridge University Press, New York, 135-207.

Goldin, Claudia and Lawrence F. Katz. 2007. "Long-Run Changes in the Wage Structure: Narrowing, Widening, Polarizing." Brookings Papers on Economic Activity 2, 135-165.

Goldin, Claudia and Robert Margo. 1992. "The Great Compression: The Wage Structure in the United States at Mid-Century." Quarterly Journal of Economics 107(1), 1-34.

Goos, Maarten, Alan Manning and Anna Salomons. 2009. "The Polarization of the European Labor Market." American Economic Review Papers and Proceedings 99(2), 58-63.

Hammermesh, Daniel, 1999. "Changing Inequality in Markets for Workplace Amenities." Quarterly Journal of Economics 114(4), 1085-1123. 
Hanushek, Eric A. and Ludger Woessmann. 2008. "The Role of Cognitive Skills in Economic Development." Journal of Economic Literature, 46(3), 607-668.

Heckman, James, and Paul LaFontaine. 2010. "The American High School Graduation Rate: Trends and Levels." Review of Economics and Statistics 92(2), 244-262.

Katz, Lawrence F. and Kevin M. Murphy. 1992. "Changes in Relative Wages 1963-1987: Supply and Demand Factors." Quarterly Journal of Economics 107(1), 35-78.

Krueger, Alan and Mikael Lindahl. 2001. "Education for Growth: Why and for Whom?" Journal of Economic Literature 39(4), 1101-1136.

Moravec, Hans. 1988. Mind Children. Harvard University Press, Cambridge.

Oreopoulos, Philip and Kjell G. Salvanes. 2011. "Priceless: The Nonpecuniary Benefits of Schooling." Journal of Economic Perspectives 25(1), 159-184.

Pierce, Brooks, 2001. "Compensation Inequality." Quarterly Journal of Economics 116(4), $1493-1525$.

Pierce, Brooks, 2010. "Recent Trends in Compensation Inequality." In Abraham, K., Harper, M., Spletzer, J. (Eds.), Labor in the New Economy, University of Chicago Press, Chicago, 63-98.

Ruggles, Steven J., Trent Alexander, Katie Genadek, Ronald Goeken, Matthew B. Schroeder, and Matthew Sobek. 2010. Integrated Public Use Microdata Series: Version 5.0 [Machinereadable database]. Minneapolis: University of Minnesota.

Tinbergen, Jan. 1974. "Substitution of Graduate by other Labour." Kyklos 27(2), 217-226.

Welch, Finis. 1973. "Black-White Differences in Returns to Schooling." American Economic Review 63(5), 893-907. 
Table 1. Regression Models for the Change in the College/High-School Log Wage Gap, 1963-2008

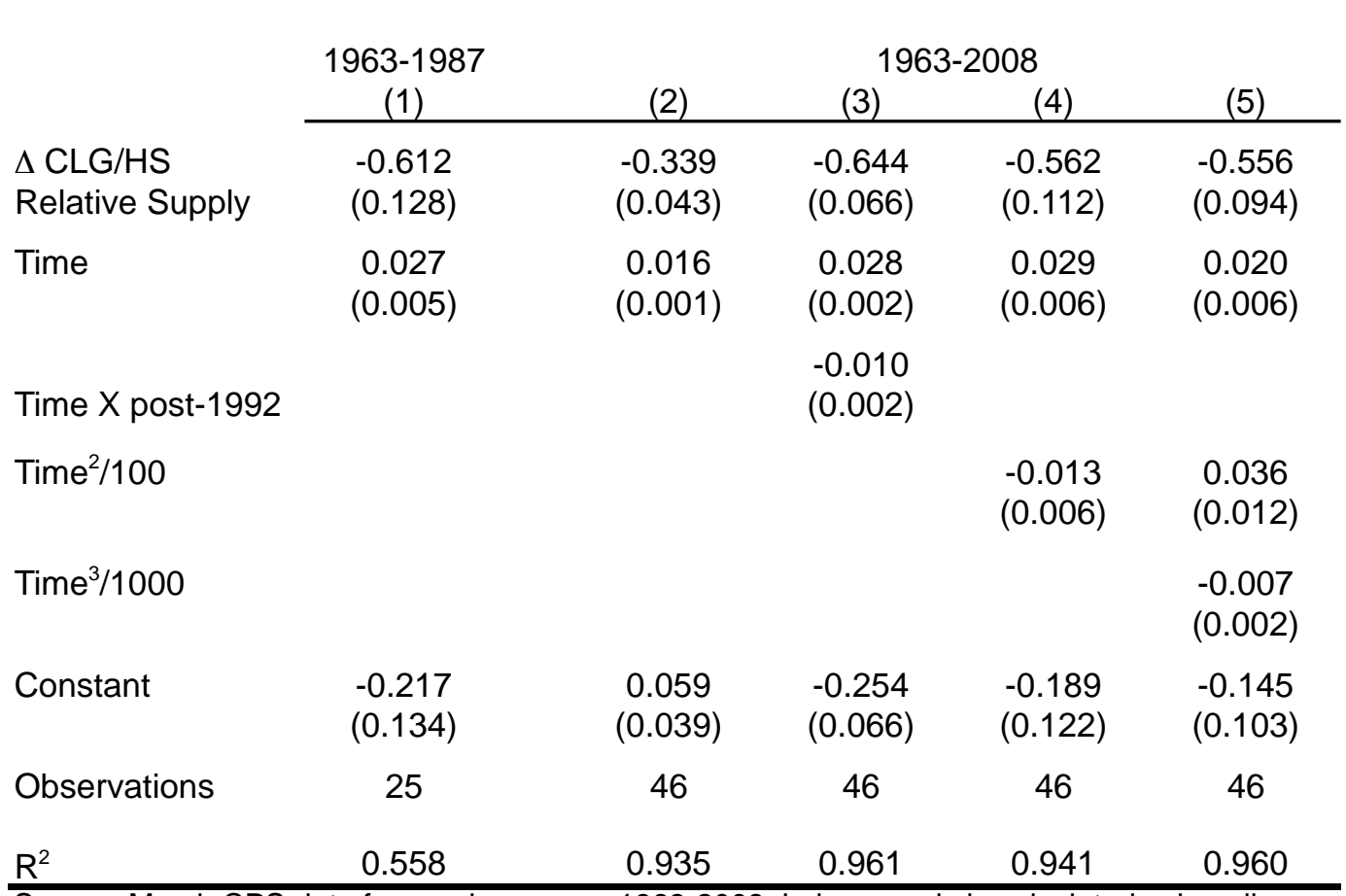

Source: March CPS data for earnings years 1963-2008. Labor supply is calculated using all persons ages 16-64 who reported having worked at least one week in the earnings years, excluding those in the military. The data are sorted into sex-education-experience groups of two sexes (male/female), five education groups (high school dropout, high school graduate, some college, college graduate, and greater than college) and 49 experience groups ( $0-48$ years of potential experience). Number of years of potential experience is calculated by subtracting the six (the age at which one begins school) and the number of years of schooling from the age of the individual. Labor supply for college/high-school groups, by experience level, is calculated using efficiency units. Efficiency units are the mean labor supply for broad college (including college graduates and greater than college) and high-school (including high school dropouts and high school graduate) categories, weighted by fixed relative average wage weights for each cell. The labor supply of the "some college" category is divided equally between the broad college and high-school categories.

Log weekly wages for full-time, full-year workers are regressed in each year on four education dummies (high school dropout, some college, college graduate, greater than college), a quartic in experience, interactions of the education dummies and experience quartic, and two race categories (black, non-white other). The composition-adjusted mean log wage is the predicted log wage evaluated for whites at the relevant experience level $(5,15,25,35,45$ years) and relevant education level (high school dropout, high school graduate, some college, college graduate, greater than college). The mean log wage for college and high school is the weighted average of the relevant composition adjusted cells using a fixed set of weights equal to the average employment share of each group. 
Table 2. Pooled 20-Year Changes in Log Per Capita Income, with Detailed Education Categories and Interactions with Initial Income or Fraction of Skilled Jobs

\begin{tabular}{|c|c|c|c|c|c|c|c|c|}
\hline & (1) & (2) & (3) & (4) & (5) & (6) & (7) & (8) \\
\hline $\log \mathrm{PI}_{-1}$ & $\begin{array}{l}-0.401 \\
(0.059)\end{array}$ & $\begin{array}{l}-0.415 \\
(0.057)\end{array}$ & $\begin{array}{l}-0.401 \\
(0.059)\end{array}$ & $\begin{array}{l}-0.435 \\
(0.056)\end{array}$ & $\begin{array}{l}-0.343 \\
(0.058)\end{array}$ & $\begin{array}{c}-0.312 \\
(0.055)\end{array}$ & $\begin{array}{l}-0.312 \\
(0.057)\end{array}$ & $\begin{array}{c}-0.330 \\
(0.057)\end{array}$ \\
\hline School (yrs) -1 & $\begin{array}{l}-0.011 \\
(0.032)\end{array}$ & $\begin{array}{l}-0.022 \\
(0.031)\end{array}$ & $\begin{array}{l}-0.012 \\
(0.033)\end{array}$ & $\begin{array}{c}0.003 \\
(0.032)\end{array}$ & $\begin{array}{c}0.125 \\
(0.045)\end{array}$ & $\begin{array}{c}0.117 \\
(0.042)\end{array}$ & $\begin{array}{c}0.135 \\
(0.045)\end{array}$ & $\begin{array}{c}0.126 \\
(0.043)\end{array}$ \\
\hline Task Complexity & $\begin{array}{l}1.391 \\
(0.261)\end{array}$ & $\begin{array}{l}1.295 \\
(0.254)\end{array}$ & $\begin{array}{c}1.391 \\
(0.262)\end{array}$ & $\begin{array}{c}1.231 \\
(0.249)\end{array}$ & $\begin{array}{c}0.826 \\
(0.286)\end{array}$ & $\begin{array}{c}0.480 \\
(0.272)\end{array}$ & $\begin{array}{l}0.610 \\
(0.285)\end{array}$ & $\begin{array}{c}0.503 \\
(0.274)\end{array}$ \\
\hline$\Delta$ School (yrs) & $\begin{array}{c}0.097 \\
(0.032)\end{array}$ & $\begin{array}{c}0.072 \\
(0.032)\end{array}$ & $\begin{array}{c}0.097 \\
(0.033)\end{array}$ & $\begin{array}{c}0.084 \\
(0.031)\end{array}$ & & & & \\
\hline$\Delta$ School $\times$ Task Complexity -1 & & $\begin{array}{c}1.427 \\
(0.423)\end{array}$ & & $\begin{array}{c}2.462 \\
(0.549)\end{array}$ & & & & \\
\hline$\Delta$ School $\times \log \mathrm{PI}_{-1}$ & & & $\begin{array}{c}0.014 \\
(0.128)\end{array}$ & $\begin{array}{l}-0.458 \\
(0.160)\end{array}$ & & & & \\
\hline$\Delta$ Primary+Secondary School & & & & & $\begin{array}{c}0.354 \\
(0.070)\end{array}$ & $\begin{array}{c}0.311 \\
(0.065)\end{array}$ & $\begin{array}{c}0.346 \\
(0.068)\end{array}$ & $\begin{array}{c}0.315 \\
(0.066)\end{array}$ \\
\hline$\Delta$ Post-Secondary School & & & & & $\begin{array}{l}-0.040 \\
(0.046)\end{array}$ & $\begin{array}{l}-0.090 \\
(0.043)\end{array}$ & $\begin{array}{l}-0.076 \\
(0.047)\end{array}$ & $\begin{array}{l}-0.079 \\
(0.044)\end{array}$ \\
\hline $\begin{array}{l}\Delta \text { Primary+Secondary School } \\
\times \text { Task Complexity }_{-1}\end{array}$ & & & & & & $\begin{array}{l}-0.460 \\
(0.688)\end{array}$ & & $\begin{array}{c}0.441 \\
(1.163)\end{array}$ \\
\hline $\begin{array}{l}\Delta \text { Post-Secondary School } \times \\
\text { Task Complexity }_{-1}\end{array}$ & & & & & & $\begin{array}{l}3.028 \\
(0.573)\end{array}$ & & $\begin{array}{l}3.107 \\
(0.827)\end{array}$ \\
\hline $\begin{array}{l}\Delta \text { Primary+Secondary School } \\
\times{\operatorname{Log~} \mathrm{PI}_{-1}}\end{array}$ & & & & & & & $\begin{array}{l}-0.099 \\
(0.130)\end{array}$ & $\begin{array}{l}-0.216 \\
(0.205)\end{array}$ \\
\hline 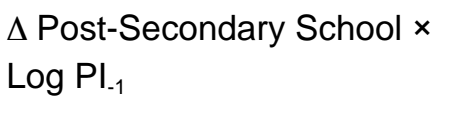 & & & & & & & $\begin{array}{l}0.625 \\
(0.210)\end{array}$ & $\begin{array}{l}-0.158 \\
(0.275)\end{array}$ \\
\hline $\mathrm{R}^{2}$ & 0.38 & 0.42 & 0.38 & 0.45 & 0.44 & 0.53 & 0.48 & 0.54 \\
\hline $\begin{array}{l}\mathrm{n}=153 \text { pooled changes. Standard } \\
\text { changes in state per-capita incom } \\
\text { length). State } \mathrm{PCl} \text { is from Census } \\
\text { Survey data for years } 2006-2008 \text {. } \\
\text { Community Survey data sources } \\
\text { equals the start-of-period fraction } \\
\text { also include an intercept and time }\end{array}$ & $\begin{array}{l}\text { errors in } \\
\text { le }(\mathrm{PCl}) \mathrm{be} \\
\text { Bureau Ir } \\
\text { All righthe } \\
\text { following } \mathrm{t} \\
\text { of state e } \\
\text { period du }\end{array}$ & $\begin{array}{l}\text { arenthese } \\
\text { tween } 196 \\
\text { come Surv } \\
\text { nd side va } \\
\text { ie procedu } \\
\text { iployment } \\
\text { nmies. }\end{array}$ & $\begin{array}{l}\text { iables ar } \\
\text { es in Ace } \\
\text { in profes }\end{array}$ & $\begin{array}{l}\text { calculate } \\
\text { ioglu anc } \\
\text { nal, mar }\end{array}$ & $\begin{array}{l}\text { gressions } \\
\text { nd } 2000-2 \\
\text { hrough } 20 \\
\text { from Cens } \\
\text { Autor (201 } \\
\text { gerial and }\end{array}$ & $\begin{array}{l}\text { Depende } \\
07 \text { (norn } \\
00 \text { and Ar } \\
\text { us IPUM } \\
\text { )). Task C } \\
\text { technical }\end{array}$ & $\begin{array}{l}\text { and Ame } \\
\text { mplexity } \\
\text { ccupatio }\end{array}$ & $\begin{array}{l}\text { stacked } \\
\text { eriod } \\
\text { Imunity } \\
\text { can } \\
\text { easure } \\
\text { Models }\end{array}$ \\
\hline
\end{tabular}




\section{Figure 1}

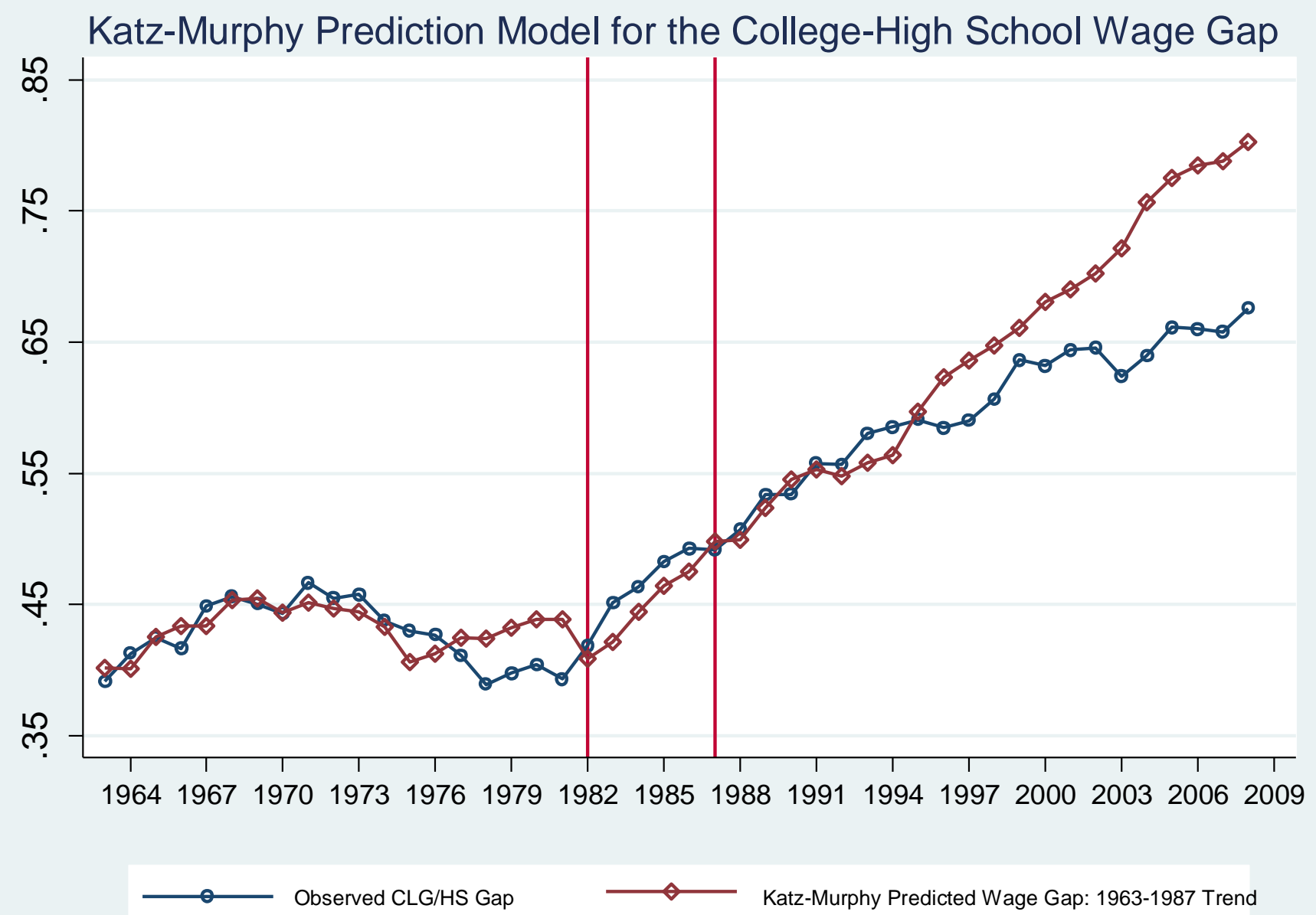

Source: March CPS data for earnings years 1963-2008. Log weekly wages for full-time, full-year workers are regressed in each year on four education dummies (high school dropout, some college, college graduate, greater than college), a quartic in experience, interactions of the education dummies and experience quartic, and two race categories (black, non-white other). The composition-adjusted mean log wage is the predicted log wage evaluated for whites at the relevant experience level $(5,15,25,35,45$ years) and relevant education level (high school dropout, high school graduate, some college, college graduate, greater than college). The mean log wage for college and high school is the weighted average of the relevant composition adjusted cells using a fixed set of weights equal to the average employment share of each group. The ratio of mean log wages for college and high school graduates for each year is plotted. See Data Appendix for more details on treatment of March CPS data. The Katz-Murphy predicted wage gap are the predicted values from a regression of the college/high-school wage gap on time trend term and log labor supply, as measured in efficiency units, for years 1963-1987. 
Figure 2

Detrended Changes in College/High-School Relative Supply and Relative Wages

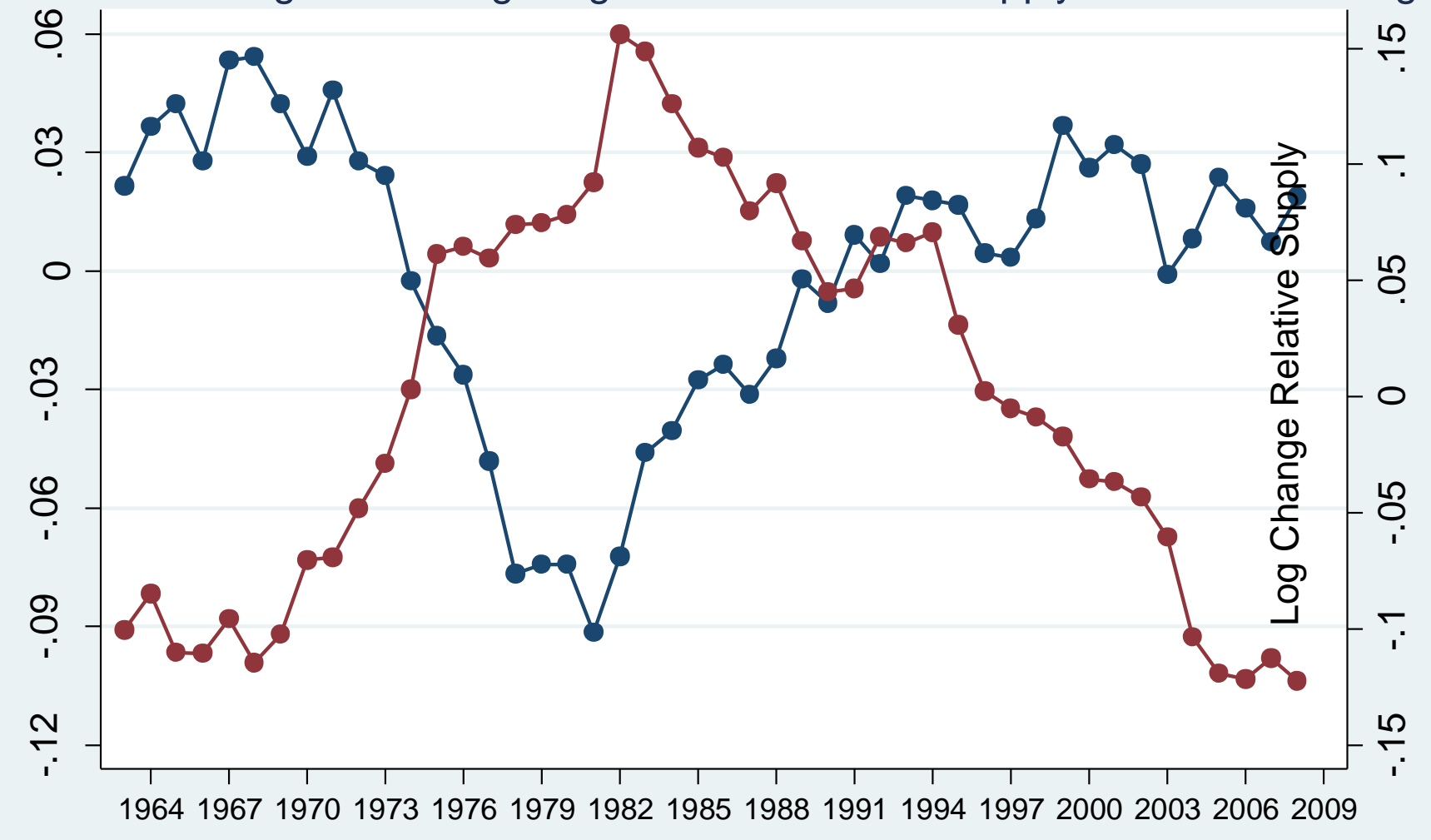

Log Change Relative Wage L_— Log Change Relative Supply

Source: March CPS data for earnings years 1963-2008. See notes to Figure 1. The detrended supply and wage series are the residuals from separate OLS regressions of the relative supply and relative wage measures on a constant and a linear time trend. 


\section{Figure 3}

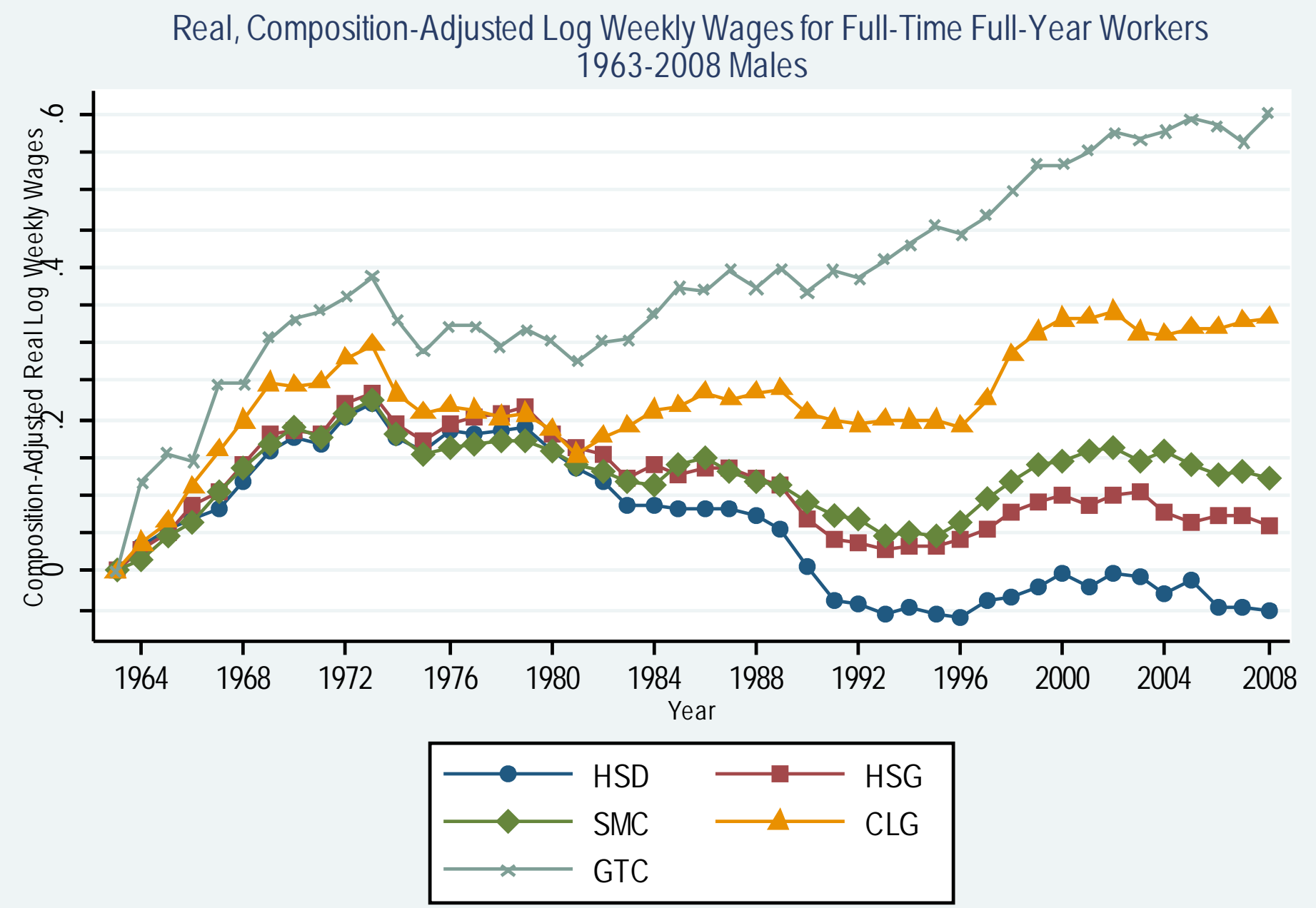

Source: March CPS data for earnings years 1963-2008. See note to Figure 1. The real log weekly wage for each education group is the weighted average of the relevant composition adjusted cells using a fixed set of weights equal to the average employment share of each group. 
Figure 4

Changes in Male Log Hourly Wages by Percentile Relative to the Median

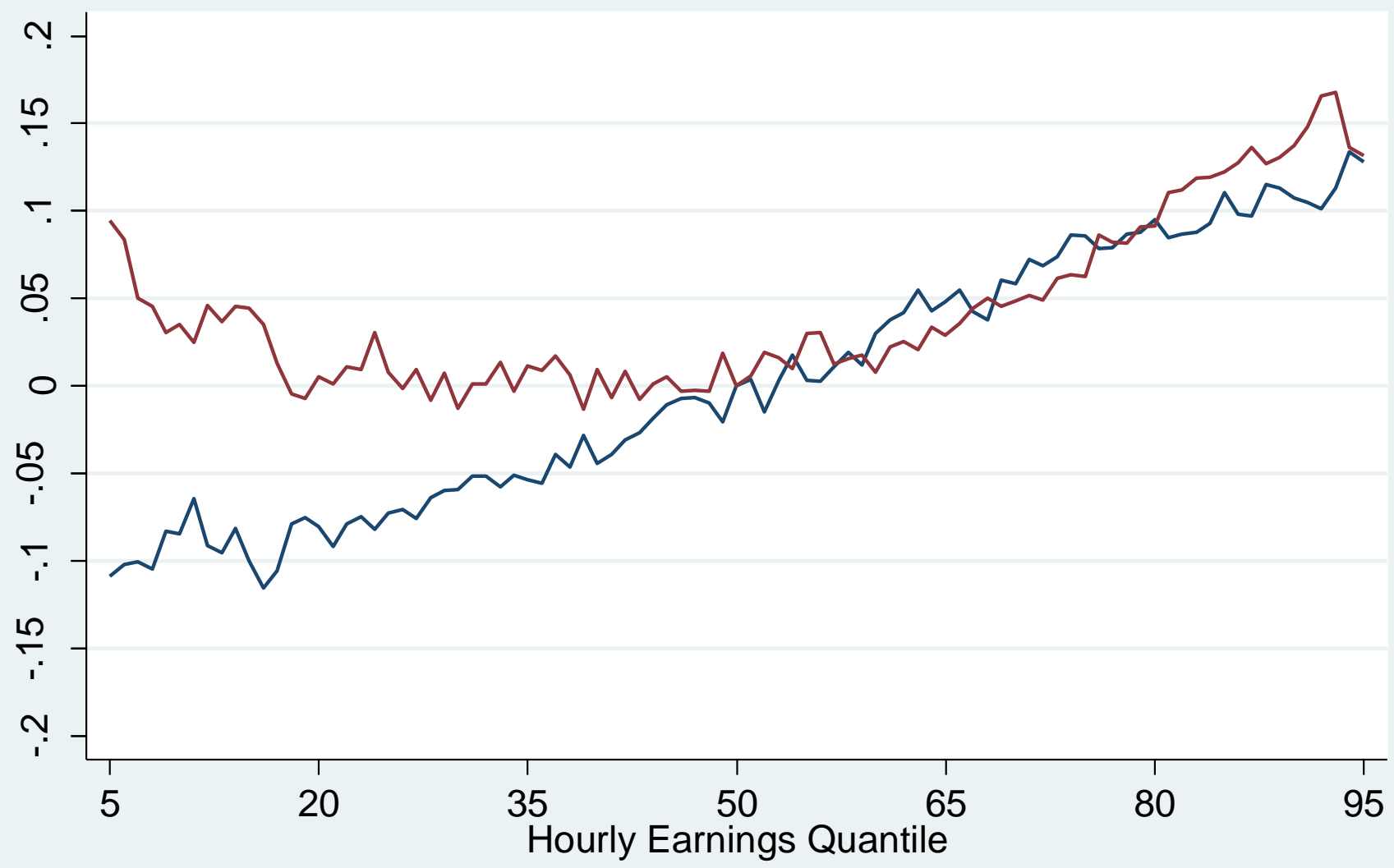

Source: May/ORG CPS data for earnings years 1973-2009. The data are pooled using three-year moving averages (i.e. the year 1974 includes data from years 1973, 1974 and 1975). For each denoted time period, the change in the $5^{\text {th }}-95^{\text {th }}$ percentile of log weekly wages is calculated. 


\section{Figure 5}

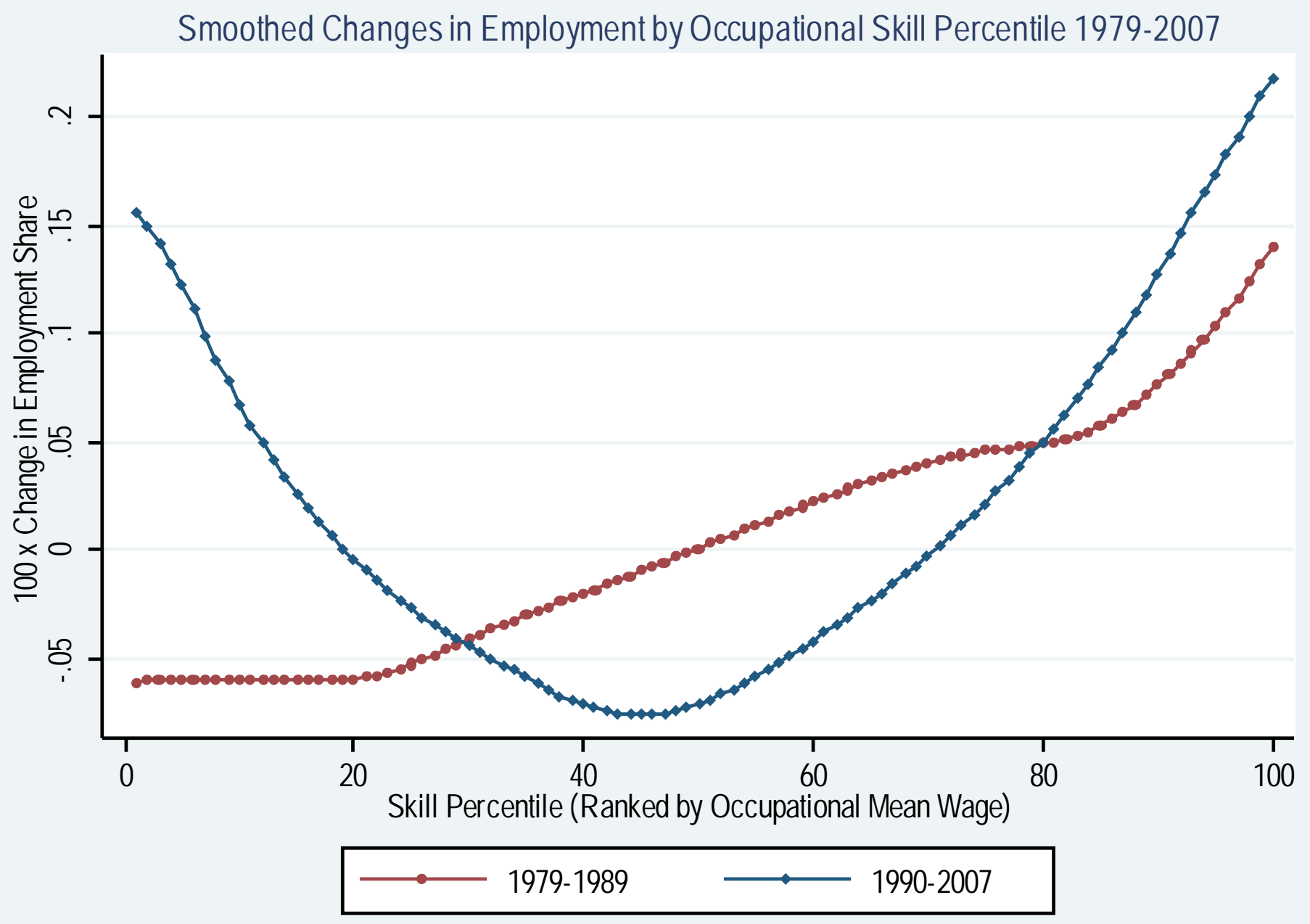

Source: Census IPUMS 5 percent samples for years 1980, 1990, and 2000, and Census American Community Survey for 2008. All occupation and earnings measures in these samples refer to prior year's employment. The figure plots log changes in employment shares by 1980 occupational skill percentile rank using a locally weighted smoothing regression (bandwidth 0.8 with 100 observations), where skill percentiles are measured as the employment-weighted percentile rank of an occupation's mean log wage in the Census IPUMS 19805 percent extract. Mean education in each occupation is calculated using workers' hours of annual labor supply times the Census sampling weights. Consistent occupation codes for Census years 1980, 1990, and 2000, and 2008 are from Autor and Dorn (2011). 


\section{Figure 6}

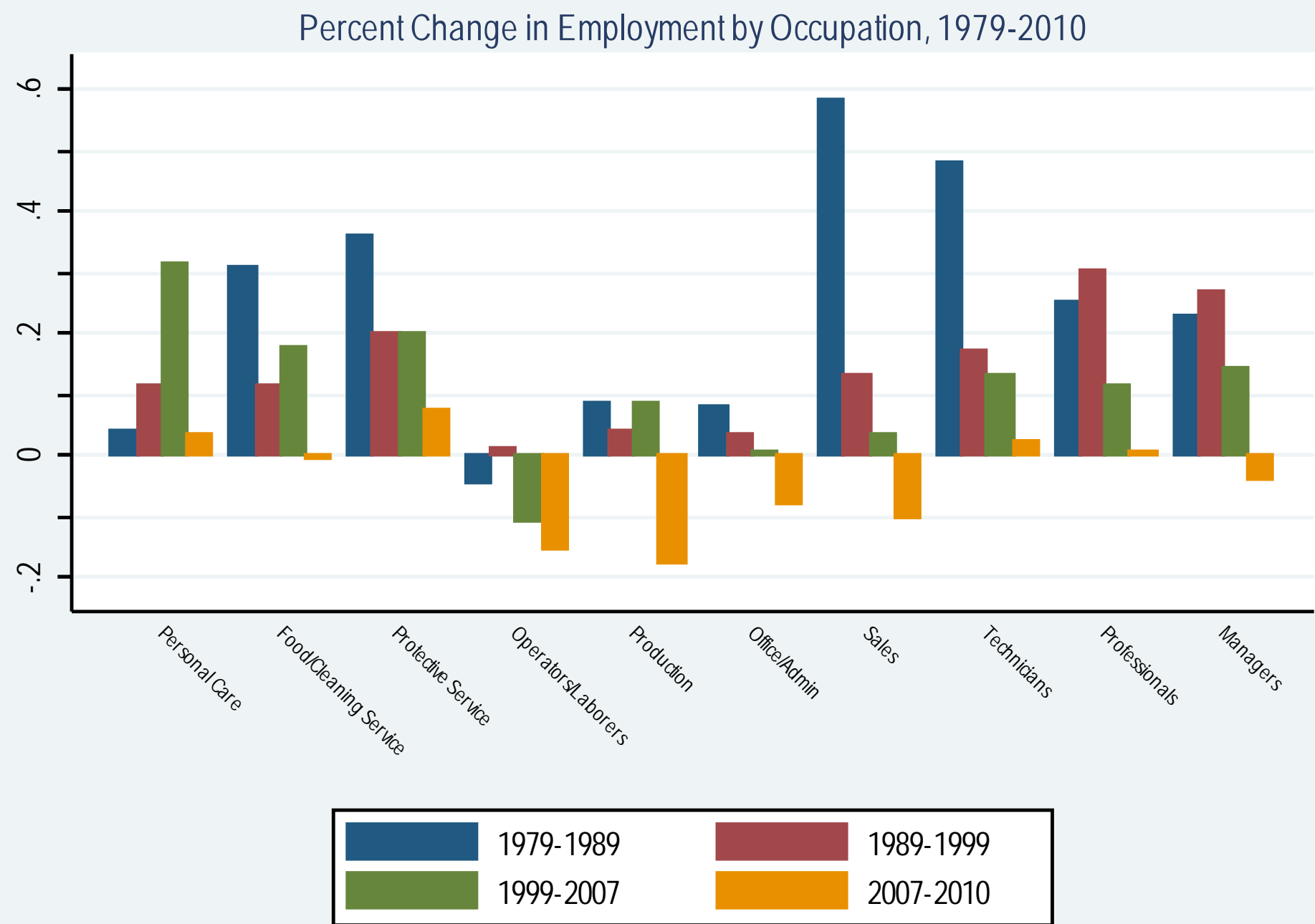

Source: May/ORG CPS files for earnings years 1979-2010. The data include all persons ages 16-64 who reported having worked last year, excluding those employed by the military and in agricultural occupations. Occupations are first converted from their respective scheme into 326 occupation groups consistent over the given time period. All nonmilitary, non-agriculture occupations are assigned to one of ten broad occupations presented in the figure. 
Figure 7. U.S. High School Graduation Rate

Overall and by Sex, 1930-1991

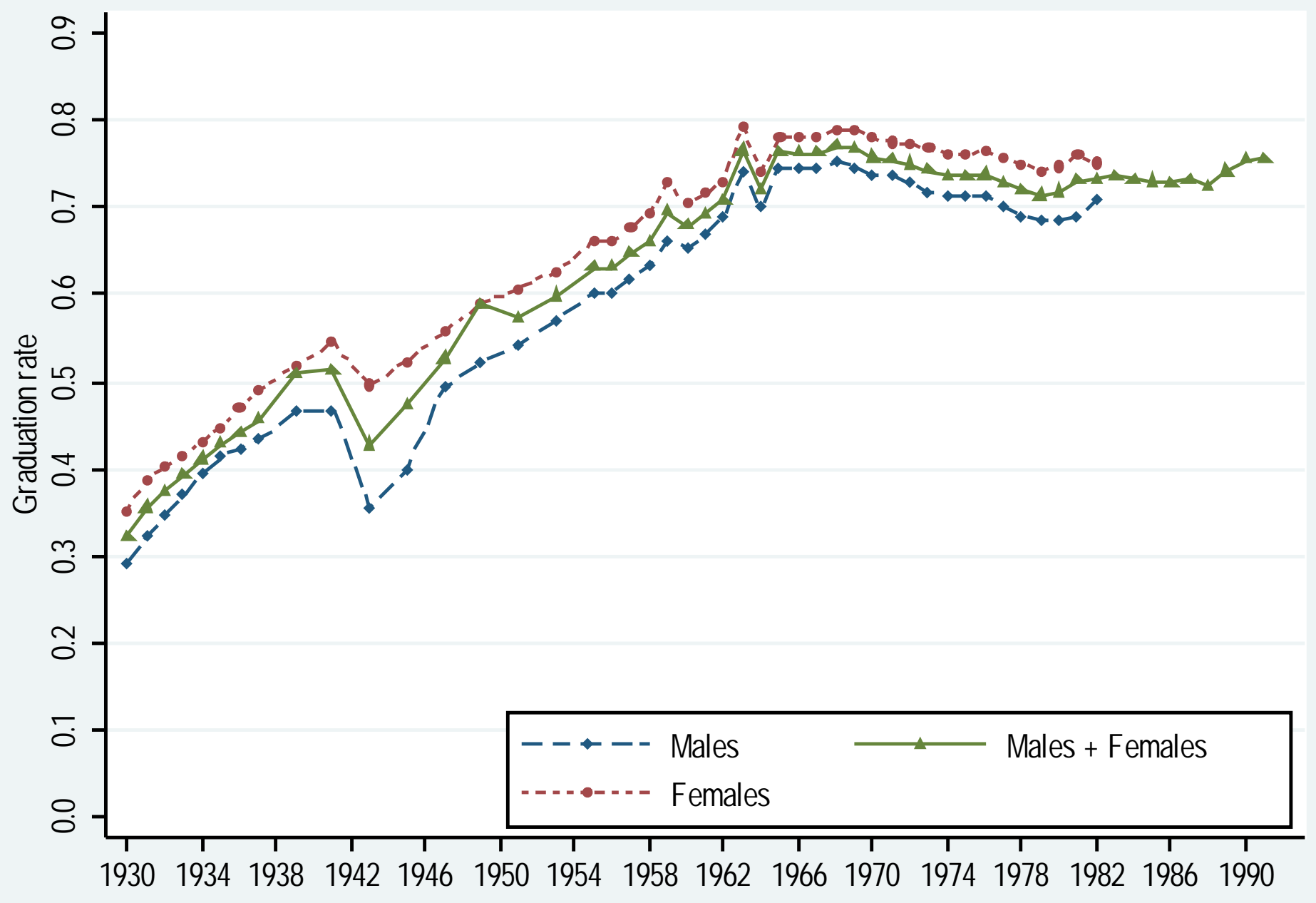




\section{Figure 8}

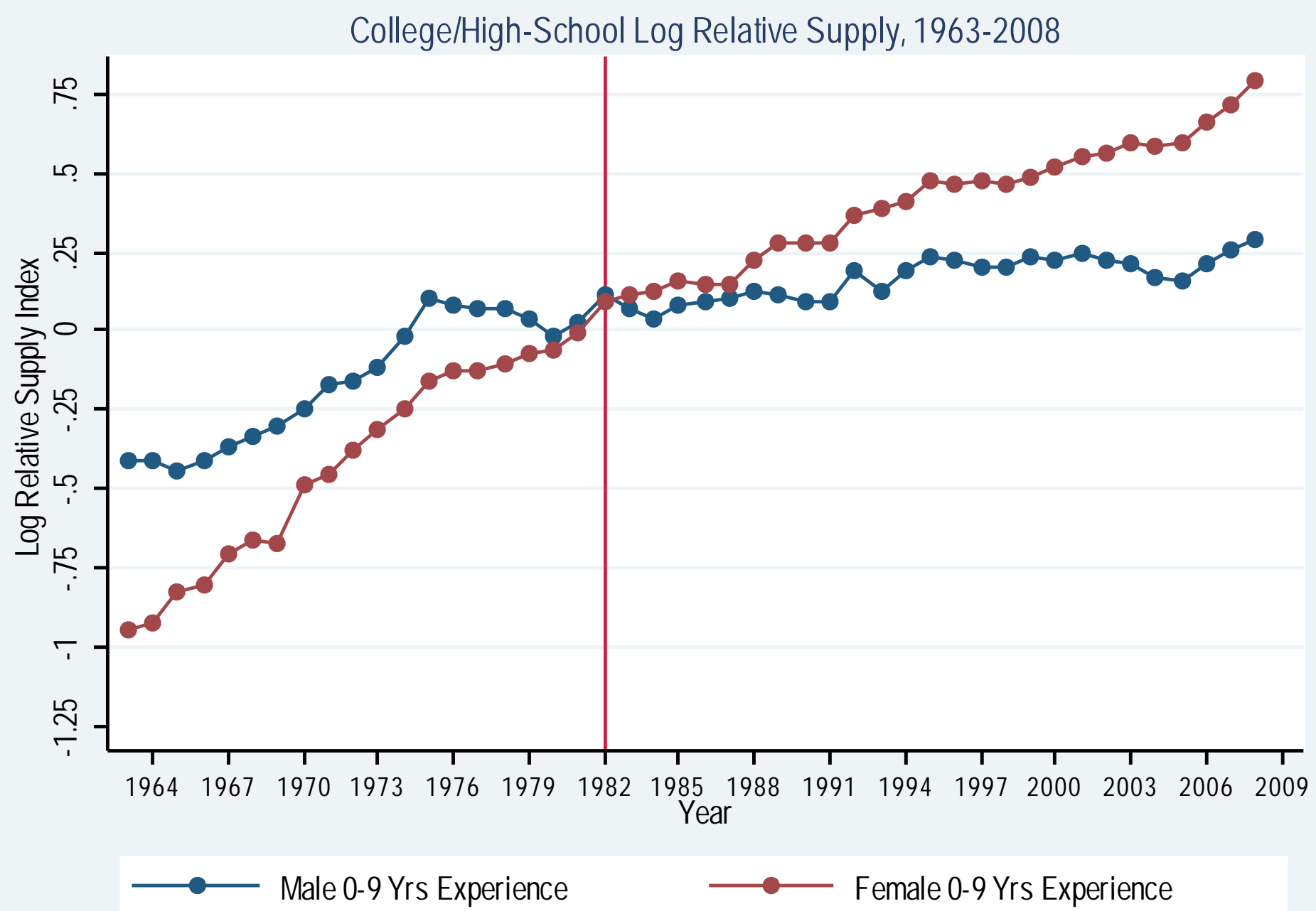

Source: March CPS data for earnings years 1963-2008. See note to Figure 1. Log relative supply for 0-9 and 20-29 years of potential experience is plotted for males and females. 